Nat. Hazards Earth Syst. Sci., 18, 2241-2260, 2018

https://doi.org/10.5194/nhess-18-2241-2018

(C) Author(s) 2018. This work is distributed under

the Creative Commons Attribution 4.0 License.

\title{
From tsunami risk assessment to disaster risk reduction - the case of Oman
}

\author{
Ignacio Aguirre-Ayerbe ${ }^{1}$, Jara Martínez Sánchez ${ }^{1}$, Íñigo Aniel-Quiroga ${ }^{1}$, Pino González-Riancho ${ }^{2}$, María Merino ${ }^{1}$, \\ Sultan Al-Yahyai ${ }^{3}$, Mauricio González ${ }^{1}$, and Raúl Medina ${ }^{1}$ \\ ${ }^{1}$ Environmental Hydraulics Institute - IHCantabria, University of Cantabria, Santander, 39011, Spain \\ ${ }^{2}$ GFA Consulting Group, Hamburg, 22359, Germany \\ ${ }^{3}$ Directorate General of Meteorology and Air Navigation, Public Authority for Civil Aviation, Muscat, 111, Oman
}

Correspondence: Ignacio Aguirre-Ayerbe (ignacio.aguirre@unican.es)

Received: 20 December 2017 - Discussion started: 9 January 2018

Revised: 18 June 2018 - Accepted: 10 July 2018 - Published: 24 August 2018

\begin{abstract}
Oman is located in an area of high seismicity, facing the Makran Subduction Zone, which is the major source of earthquakes in the eastern border of the Arabian plate. These earthquakes, as evidenced by several past events, may trigger a tsunami event. The aim of this work is to minimize the consequences that tsunami events may cause in coastal communities by integrating tsunami risk assessment and risk reduction measures as part of the risk-management preparedness strategy. An integrated risk assessment approach and the analysis of site-specific conditions permitted to propose target-oriented risk reduction measures. The process included a participatory approach, involving a panel of local stakeholders and international experts. One of the main concerns of this work was to obtain a useful outcome for the actual improvement of tsunami risk management in Oman. This goal was achieved through the development of comprehensive and functional management tools such as the Tsunami Hazard, Vulnerability and Risk Atlas and the Risk Reduction Measures Handbook, which will help to design and plan a roadmap towards risk reduction.

The integrated tsunami risk assessment performed showed that the northern area of Oman would be the most affected, considering both the hazard and vulnerability components. This area also concentrates nearly $50 \%$ of the hot spots identified throughout the country, $70 \%$ of them are located in areas with a very high risk class, in which risk reduction measures were selected and prioritized.
\end{abstract}

\section{Introduction}

Tsunamis are low-frequency natural events but have a great destructive power when striking coasts around the world, involving loss of life and extensive damage to infrastructure and coastal communities worldwide. Between 1996 and 2015, estimated tsunami disaster losses reached 250000 lives, more than 3500000 affected people and more than USD 220000 million (International Disaster Database, EMDAT; UNISDR/CRED, 2016).

Oman is located in an area of high seismicity, facing the Makran Subduction Zone (MSZ), which is the major source of earthquakes in the eastern border of the Arabian plate (Al-Shaqsi, 2012). These earthquakes may trigger a tsunami event, as evidenced at least three times in the past (Heidarzadeh et al., 2008; Jordan, 2008). The high potential for tsunami generation of MSZ makes it one of the most tsunamigenic areas of the Indian Ocean. The most recent tsunami event of seismic origin was the 1945 Makran tsunami, which caused more than 4000 fatalities and property losses in Iran, Pakistan, Oman and the United Arab Emirates (Heck, 1947; Heidarzadeh et al., 2008, 2009; Heidarzadeh and Kijko, 2011; Heidarzadeh and Satake, 2014a, b; Mokhtari, 2011, Latcharote et al., 2017). Similar episodes may occur again in this area.

In addition to the tsunami threat on the coast of Oman, the rapid development and industrialization of this area explains the need to develop specific studies on tsunami vulnerability and risk, especially in the northern low-lying coastal plain, which is the most densely populated and most exposed to the MSZ. 
Suitable tsunami vulnerability and risk assessments are essential for the identification of the exposed areas and the most vulnerable communities and elements. They allow identifying appropriate site-specific risk management strategies and measures, thus enabling to mainstream disaster risk reduction (DRR) into development policies, plans and programmes at all levels including prevention, mitigation, preparedness, and vulnerability reduction, considering its root causes.

Most methods for risk assessment are quantitative or semi quantitative (usually indicator-based). Quantitative risk assessments are generally better related to the analysis of specific impacts, which require large scales and high resolution for all the components contributing the risk. Results are usually expressed in terms of potential losses both economic (derived from building damage or even infrastructure damage) and human (derived from mortality estimations). There are several works following this approach, among others Tinti et al. (2011) and Valencia et al. (2011) within the frame of the SCHEMA Project (2007-2010), Leone et al. (2011), Suppasri et al. (2011, 2013, 2018), Mas et al. (2012), and Shoji and Nakamura (2017), with a main focus on infrastructure and building damage. Sato et al. (2003), Sugimoto et al. (2003), Koshimura et al. (2006), Jonkman et al. (2008) and Løvholt et al. (2014) focused on human damage and casualties whereas Berryman (2005) and Harbitz et al. (2016) dealt with both aspects.

Although not as common, quantitative risk assessments are sometimes applied at global scale such as the case of the GRM - Global Risk Model (last version in the UNISDR Global Assessment Report, UNISDR, 2017), which addresses a probabilistic risk model at a world scale to assess economic losses based on buildings damage (Cardona et al., 2015).

However, when the scope requires a holistic and integrated approach in which several dimensions, criteria and variables with different magnitudes and ranges of values have to be taken into consideration, such as the case of the present work, it is necessary to apply an indicator-based method. Some works following this approach may be found in ESPON (2006), Dall'Osso et al. (2009), Dall'Osso and Dominey-Howes (2009), Taubenböck et al. (2008), Jelínek (2009, 2012), Birkmann et al. (2010, 2013), Strunz et al. (2011), Aguirre-Ayerbe (2011), Wegscheider et al. (2011), González-Riancho et al. (2014), the TRANSFER project (2006-2009), the Coasts at Risk report (Beck, 2014), the World Risk Report (last version: Garschagen et al., 2016) and the INFORM Global Risk Index (INFORM, 2017).

Nevertheless, very few of the previous works tackle with the direct link between integrated tsunami risk results and risk reduction measures (RRM). González-Riancho et al. (2014) propose a translation of risk results into disaster risk management options and Suppasri et al. (2017) describe some recommendations based on the lessons learned in recent tsunamis.

Therefore, it has been identified that there is not a clear applicability of science-based tsunami hazard and vulnerability tools to improve actual DRR efforts, highlighting a general disconnection between technical and scientific studies and risk management.

This work attempts to be complementary to preceding efforts and to fill the gap found in previous studies. The developed methodology is based on the direct relationship found between risk components (hazard, exposure and vulnerability) and specific DRR measures and integrates tsunami risk assessment and site-specific characteristics to select a suitable set of tsunami countermeasures. The ultimate goal is the application of the method and the generation of useful management tools to minimize the consequences that a potential tsunami could have on the coast of Oman.

\section{Methodology}

The methodology comprises two main phases: (i) the integrated tsunami risk assessment and (ii) the identification, selection and prioritization of appropriate DRR measures. These two different but complementary tasks will guide the entire methodology applied in this work.

In regard to the conceptual framework, the methodology applied is fundamentally adapted from the definitions of UNISDR (2004, 2009), ISO Guide 73 (2009), UNESCO (2009b) and UN (2016). Accordingly, the sequence of the work is summarized schematically in Fig. 1. Within the disaster risk assessment phase and prior to any risk study, it is necessary to define the consequence to be analysed and the type of result pursued (for example, the estimation of buildings damages or the community's affection from a holistic perspective, as the case presented in this article). The establishment of this main goal determines the specific method, the dimensions to include in the study and the spatial and temporal scales (point 1 of Fig. 1).

Next, the assessment of the hazard, explained in detail in Sect. 2.1, requires the selection of the variable associated to the event (e.g. flow depth), mainly determined by the general goal defined in the first step. The hazard evaluation drives the analysis of the individuals and elements exposed (e.g. people, buildings and infrastructure located in a flooded populated area) together with its vulnerability (e.g. sensitive age groups). The risk assessment is performed by the combination of the vulnerability assessment of what is exposed and the hazard intensity (points 3,4 and 5 of Fig. 1, explained in detail in Sect. 2.2 and 2.3). Exposure, vulnerability and the integration of all risk components, circumscribed to a given spatial, cultural and socioeconomic context, are necessary for the preliminary selection of risk reduction strategies and measures. These countermeasures are essential to prevent new and reduce existing risk, as stated by UN (2016), 


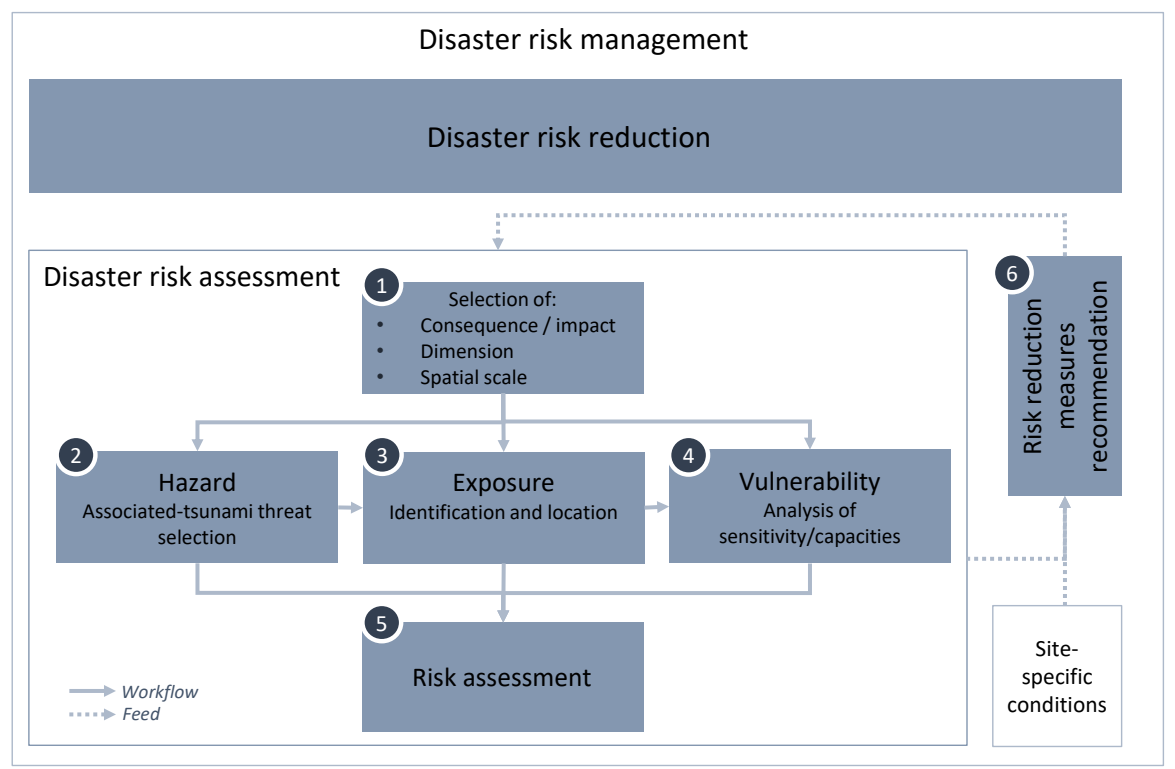

Figure 1. Schematic workflow.

contributing to the strengthening of resilience and reduction of disaster losses (point 6 in Fig. 1. - schematic workflow, detailed in Sect. 2.4).

The determination of the efficiency of each proposed countermeasure is essential for the success of the risk reduction planning. When an appropriate countermeasure is selected, the overall risk assessment must be conducted again to understand how and to what extent it will actually reduce the risk.

DRR measures are framed in the disaster risk management cycle proposed below, which brings together four main strategies for risk reduction (Fig. 2): (i) prevention and (ii) preparedness strategies in the pre-event stage and (iii) emergency response and (iv) recovery in the post-event phase. Each of the strategies includes several actions that may be overlapped on time and that may even belong to more than one strategy. At the centre of the figure, research is presented as an essential element to improve disaster management enriching the process through the integration of various disciplines and studies. This particular study focuses on the strategies related to the pre-event phase: the prevention and the preparedness, which are explained in Sect. 2.4.

Risk and vulnerability assessments are performed both for a specific place and at a specific time. For this reason, both the analysis and the proposal of measures for risk reduction must be updated periodically, considering the changes that may occur over time and their influence on the results, such as a significant variation in population, land-use changes, new constructions or new lessons learnt.

The involvement of key local stakeholders and decisionmakers in coastal risk management is essential throughout the entire process, both to include their knowledge and exper- tise and to enhance the usefulness of the results of the project throughout their encouragement. Thus, a stakeholder panel composed of local and international experts on coastal risks and risk management supported the entire process, driven to actively participate and collaborate to achieve the goal of DRR. Their main contribution focused on the validation of the methodological approach, the identification of hot spots and the analysis of the technical, institutional and financial capacities of the country for implementing each one of the countermeasures. In the last stage of the study, they prioritized each measure according to their knowledge and expertise.

\subsection{Hazard assessment}

The hazard analysis allows determining the areas that would be affected due to the potential tsunamis that may strike the study area. The analysis is carried out considering the worst possible tsunami scenarios based on the seismic-tectonic characterization of the area, so that the maximum impact that a tsunami would cause is calculated. Similar approaches may be found in Jelínek et al. (2009, 2012), Álvarez-Gómez et al. (2013) and Wijetunge (2014) among others. The deterministic tsunami hazard analysis allows identifying, locating and analysing the elements at risk in a conservative approach. It is worth considering this method when dealing with intensive risks, i.e. derived from low frequency but high severity hazards, such as tsunamis, where the catastrophic consequences of the impact are complex and difficult to estimate.

In this study, only potential earthquake sources were considered as the tsunami generation mechanism. A seismictectonic analysis was performed to identify and character- 


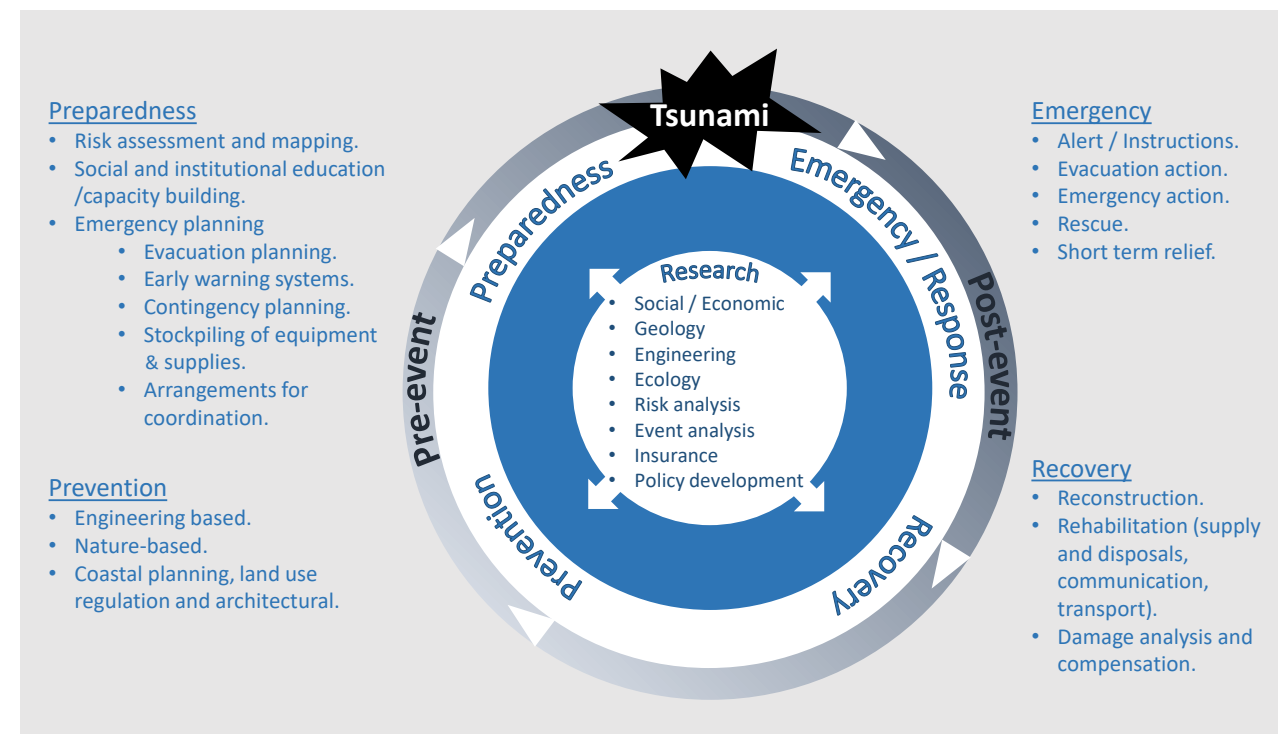

Figure 2. Disaster risk management cycle.

ize the major seismic structures with capacity to generate a tsunami affecting the coast of Oman (see Aniel-Quiroga et al., 2015). The study area was divided in three tectonically homogeneous zones including eleven main structures. The geometrical characterization of the fault planes (from the tectonics and the focal mechanisms analysis) allowed identifying 3181 focal mechanisms with a magnitude varying from $M_{\mathrm{w}} 6.5$ to 9.25 .

Once these scenarios are established, the analysis includes the characterization of the quake (fault location, magnitude, length and width of the fault, fault dislocation angles, epicentre location and focal depth of the epicentre) and the sea level. The numerical modelling applied to conduct the simulations is COMCOT (Wang, 2009), which solves shallow water equations using Okada model (Okada, 1985) model to generate the initial deformation of the sea surface. This model uses moving boundary technique for land flooding. Based on the bathymetry, the propagation of each potential tsunami is modelled from the source to the coast. Finally, according to the topography, the coastal area is flooded, with a final resolution (grid size) of $45 \mathrm{~m}$ onshore.

The approach is described in detail in Aniel-Quiroga et al. (2015) and is based on the works of Álvarez-Gómez et al. (2014) and Gutiérrez et al. (2014).

Figure 3 shows the distribution of the major seismic structures and the number of events propagated for each of them. The seismic-tectonic study was particularly focused in the Makran subduction zone, as it is possibly the most active area in the western Indian Ocean and located very near the north coast of Oman.

On one side, the complete set of the 3181 scenarios was included in a tsunami-scenarios database, which is the basis of the current early warning system in the country. On the other, seven scenarios were selected to perform the deterministic hazard assessment, including the historical event of 1945, which took place in the Makran subduction zone (Heidarzadeh et al., 2008). Hazard variables are calculated at each time step of every single simulation and then the maximum values are selected. These scenarios were aggregated into a map that shows at each point of the study area the worst possible situation. This enveloping map is the base for the risk assessment and includes the variables of flow depth (vertical distance between the water surface and the ground, also called inundation depth by some authors, e.g. Aniel-Quiroga et al., 2015), water velocity, and a proxy for the drag force, the depth-velocity product (drag level).

Hazard variables were finally classified into five levels of intensity to be subsequently combined with vulnerability, as described in Sect. 2.3. Tsunami drag level classification is based on previous works carried out by Xia et al. (2014), Jonkman et al. (2008), Karvonen et al. (2000), and Abt et al. (1989), which establish different thresholds related to human-related stability factors. As for the flow depth variable, the classification is based on the work developed in the SCHEMA project (Tinti et al., 2011) to establish building damage levels, based on empirical damage functions considering building materials and water depth.

\subsection{Vulnerability assessment}

The method applied to assess the vulnerability relies on an indicator-based approach. The process includes three main stages: (a) the definition of criteria for selecting the dimensions and variables to be analysed for the exposed elements; (b) establishment, calculation and classification of indicators; and (c) the construction of vulnerability indexes and its clas- 


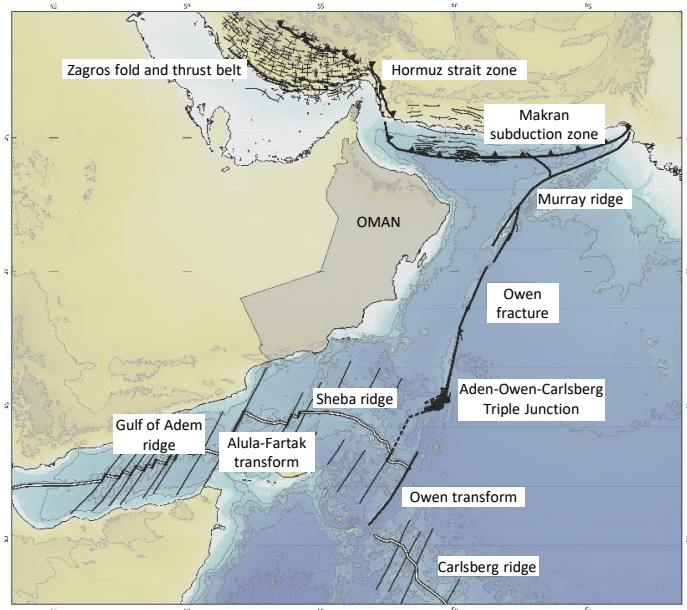

\begin{tabular}{|l|l|r|}
\hline \multicolumn{2}{|c|}{ Tectonic structure/zone } & $\begin{array}{l}\text { Events } \\
\text { propagated }\end{array}$ \\
\hline 1 & Gulf of Adem Ridge & 44 \\
\hline 2 & Alula Fartak & 1 \\
\hline 3 & Aden-Owen-Carlsberg Triple Junction & 14 \\
\hline 4 & Sheba Ridge & 65 \\
\hline 5 & Owen Transform & 3 \\
\hline 6 & Carlsberg Ridge & 74 \\
\hline 7 & Owen Fracture & 16 \\
\hline 8 & Murray Ridge & 33 \\
\hline 9 & Homuz Strait Zone & 48 \\
\hline 10 & Zagros Zone & 148 \\
\hline 11 & Makran Subduction Zone & 2735 \\
\hline
\end{tabular}

Figure 3. Main seismic areas surrounding the study area and number of events propagated for each area.

sification. These steps are explained in the following paragraphs.

Two different dimensions are selected: human and infrastructure, with the aim of developing an analysis with a human-centred perspective. On one side, the human dimension allows for analysing the intrinsic characteristics of the population. On the other side, the infrastructure dimension allows the analysis of buildings and critical facilities, to consider their potential worsening implications for the populations, following the rationale described in González-Riancho et al. (2014). In this sense, it is considered that an increase in the number of victims is likely to occur, due to the loss or damage of emergency services, or the recovery capacity may decrease due to the loss of strategic socioeconomic infrastructure such as ports.

The criteria for analysing the human dimension are the population capacities related to their mobility and evacuation speed, and the ability to understand a warning message and an alert situation. The criteria determined to analyse the infrastructure dimension are the critical buildings housing a large number of people (schools, hospitals, etc.), the emergency facilities and infrastructure, the supply of basic needs, the building and infrastructure that could generate negative cascading effects and the economic consequences.

Consequently, a set of 11 indicators has been defined (see Table 1) to develop a framework that allows for encompassing the major issues related to the community's vulnerability. This framework was developed in agreement with local stakeholders and international experts through the participatory process.

Indicators $\mathrm{H} 1$ and I1 identify and locate the amounts and types of exposed population and infrastructure, respectively, i.e. the amount of people, buildings and infrastructure located in the flooded area. The human indicators $\mathrm{H} 2-\mathrm{H} 5$ are oriented to measure weaknesses in terms of evacuation and reaction capacities of the exposed population. Specifically, $\mathrm{H} 2$ and $\mathrm{H} 3$ are related to problems with mobility and evacuation velocity whereas $\mathrm{H} 2, \mathrm{H} 3, \mathrm{H} 4$ and $\mathrm{H} 5$ are related to difficulties in understanding a warning message and an alert situation.

The infrastructure indicators I2-I6 measure the number of critical facilities and buildings that would be affected by administrative area, bearing in mind the implications for the population. I 2 provides the number of buildings that would require a coordinated and previously planned evacuation due to the high number of people in them (in some cases sensitive population), such as hospitals, schools, nursing homes, malls, stadiums, mosques, churches, etc. I3 calculates the loss of emergency services that are essential during the event. I4 reports on the potential number of power plants and desalination plants affected, hindering the long-term supply of electricity and water to local communities. I5 analyses the generation of cascading impacts that could take place due to affected hazardous or dangerous industries. Finally, I6 considers the loss of strategic ports and/or airport infrastructure, essential for the economy of the country and the local livelihoods (fishing ports).

The construction of vulnerability indexes is performed through the weighted aggregation of the previously normalized indicators via the min-max method (OECD, 2008). Aggregated indexes are then classified considering the data distribution via the natural breaks method (Jenks, 1967) and grouped in five classes, obtaining homogeneous vulnerability areas that are expected to need similar DRR measures.

Indicators and indexes have been applied to every wilayat along the coast of Oman (wilayat is an administrative division in Oman). Comparable results are obtained among all areas due to the methods of normalization and classification, which take into account the values of the index for all areas when establishing classes' thresholds. This method depends 
Table 1. Exposure and sensitivity indicators built for the tsunami vulnerability assessment in Oman.

\begin{tabular}{|c|c|c|c|}
\hline Index & & Indicator & Variable \\
\hline \multirow{5}{*}{$\begin{array}{l}\text { Human } \\
\text { vulnerability } \\
\text { index }\end{array}$} & $\begin{array}{l}\text { Human } \\
\text { exposure }\end{array}$ & H1 - Population & Number of people exposed \\
\hline & \multirow{4}{*}{$\begin{array}{l}\text { Human } \\
\text { sensitivity }\end{array}$} & $\mathrm{H} 2$ - Sensitive age groups & Number of persons $<10$ and $>65$ years old \\
\hline & & H3 - Disability & Number of disabled persons (physical and intellectual) \\
\hline & & H4 - Illiteracy & Number of illiterate persons \\
\hline & & H5 - Expatriates & Number of expatriates \\
\hline \multirow{6}{*}{$\begin{array}{l}\text { Infrastructure } \\
\text { vulnerability } \\
\text { index }\end{array}$} & $\begin{array}{l}\text { Infrastructure } \\
\text { exposure }\end{array}$ & $\begin{array}{l}\text { I1 - Buildings and } \\
\text { infrastructure }\end{array}$ & Amount of exposed buildings and infrastructure \\
\hline & \multirow[t]{5}{*}{$\begin{array}{l}\text { Infrastructure } \\
\text { sensitivity }\end{array}$} & I 2 - Critical buildings & $\begin{array}{l}\text { Amount of critical buildings (health, educational, religious, } \\
\text { cultural, and governmental) }\end{array}$ \\
\hline & & I3 - Emergency & $\begin{array}{l}\text { Amount of emergency infrastructure (civil defence, police, firemen, } \\
\text { military, and royal guard) }\end{array}$ \\
\hline & & I4 - Supply & $\begin{array}{l}\text { Amount of water supply (desalination plants) and energy supply } \\
\text { (power plants) infrastructure }\end{array}$ \\
\hline & & I5 - Dangerous & Amount of dangerous and hazardous infrastructure \\
\hline & & I6 - Strategic & Amount of strategic infrastructure (ports and airports) \\
\hline
\end{tabular}

on the distribution of the data, thus the study of any index evolution over time, for comparable purposes, must maintain the thresholds established in the initial analysis. In the same way, if new study areas were added, they should be included and new thresholds should be established.

\subsection{Risk assessment}

Risk results are obtained by combining hazard and vulnerability components through a risk matrix (Greiving et al., 2006; Jelínek et al., 2009; Aguirre-Ayerbe, 2011; GonzálezRiancho et al., 2014; Schmidt-Thomé, 2006; ESPON, 2006; IH Cantabria-MARN, 2010, 2012 projects). Classes derived from the hazard assessment are blended with vulnerability classes by means of a risk matrix, as shown in Fig. 4, to obtain two types of results: partial risks for each dimension and a combined risk result from the weighted aggregation of both dimensions. The results are finally classified into five risk classes.

The hazard variable differs according to each dimension of the study to specifically analyse the potential impacts. The combination of water depth and velocity, as a proxy for the drag force, which is related to the loss of people's stability (Jonkman et al., 2008), is applied to the human dimension. Flow depth variable is applied to the infrastructure dimension, based on empirical damage functions built from posttsunami observations, that take into account different building typologies (structure, construction material, number of storeys), flow depth and damage analysis (Tinti et al., 2011; Valencia et al., 2011).
The results obtained from the risk matrix reveal areas at high risk, which are expected to have serious negative consequences due to the combination of hazard and vulnerability conditions. In-depth analysis of these areas allows the identification of the causes of these results and to propose adequate RRM according to each of the components, dimensions and variables considered to perform the risk assessment.

\subsection{Risk reduction measures}

A method has been developed to identify, recommend and prioritize the most suitable alternatives for tsunami risk reduction, based on the risk analysis and site-specific conditions. The first step was the development of a RRM catalogue, to finally obtain a set of site-specific and target-oriented countermeasures. This method facilitates the decision-making process by connecting scientific and technical results with risk management.

The work focuses on the straightforward feedingreduction relation among the different risk components (i.e. hazard, exposure and vulnerability) and the risk reduction measures focused on the pre-event stage (see Fig. 5).

Accordingly, two main strategies are identified to achieve a long-term coastal flooding risk reduction: preparedness and prevention, which are based on the concepts defined by UN (2016) and UNISDR (2009).

Preparedness actions focus on the knowledge, capabilities and skills developed to anticipate and respond to the impacts of the event, and include the following: (i) risk assessment and mapping, (ii) social and institutional awareness, 


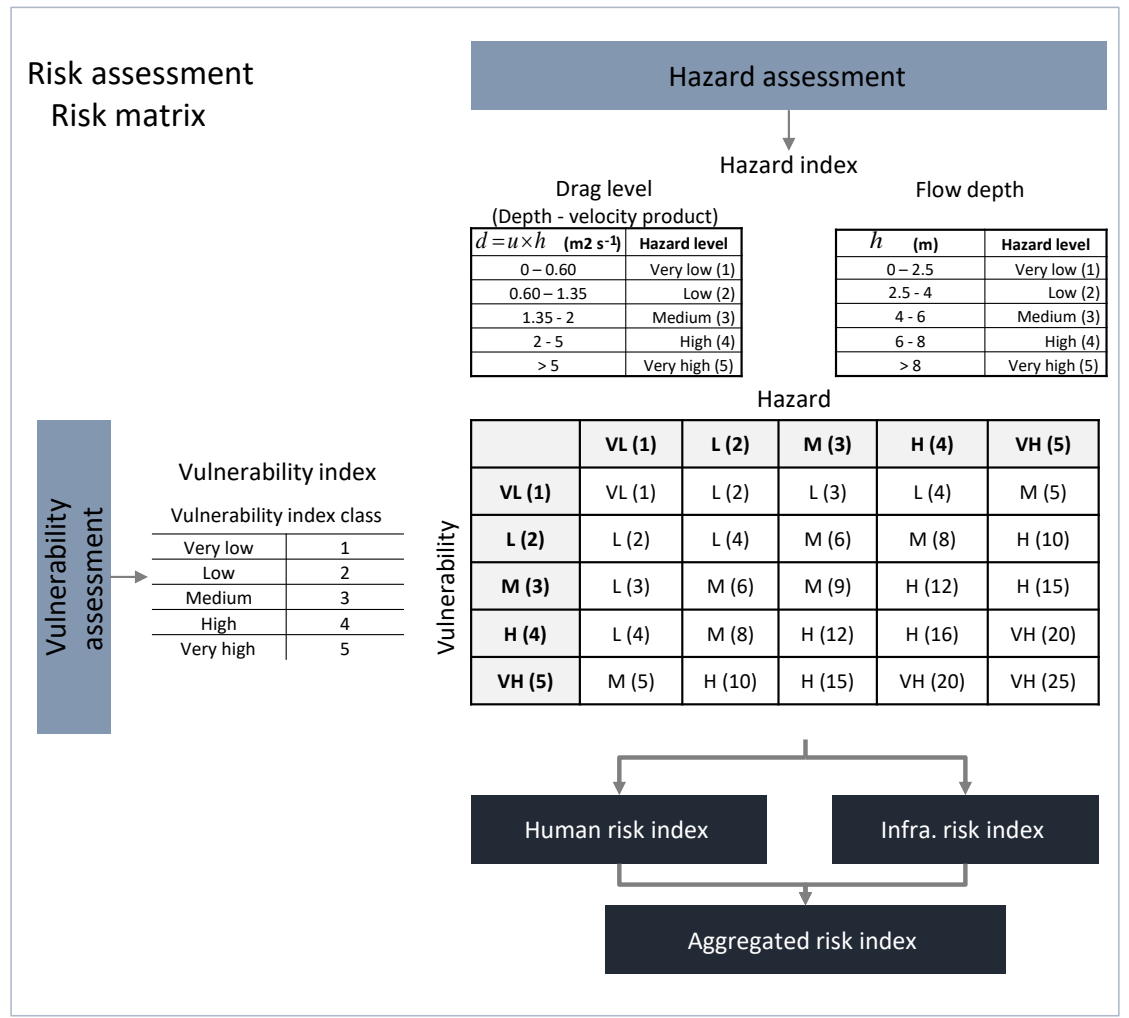

Figure 4. Risk matrix combining hazard and vulnerability classes.

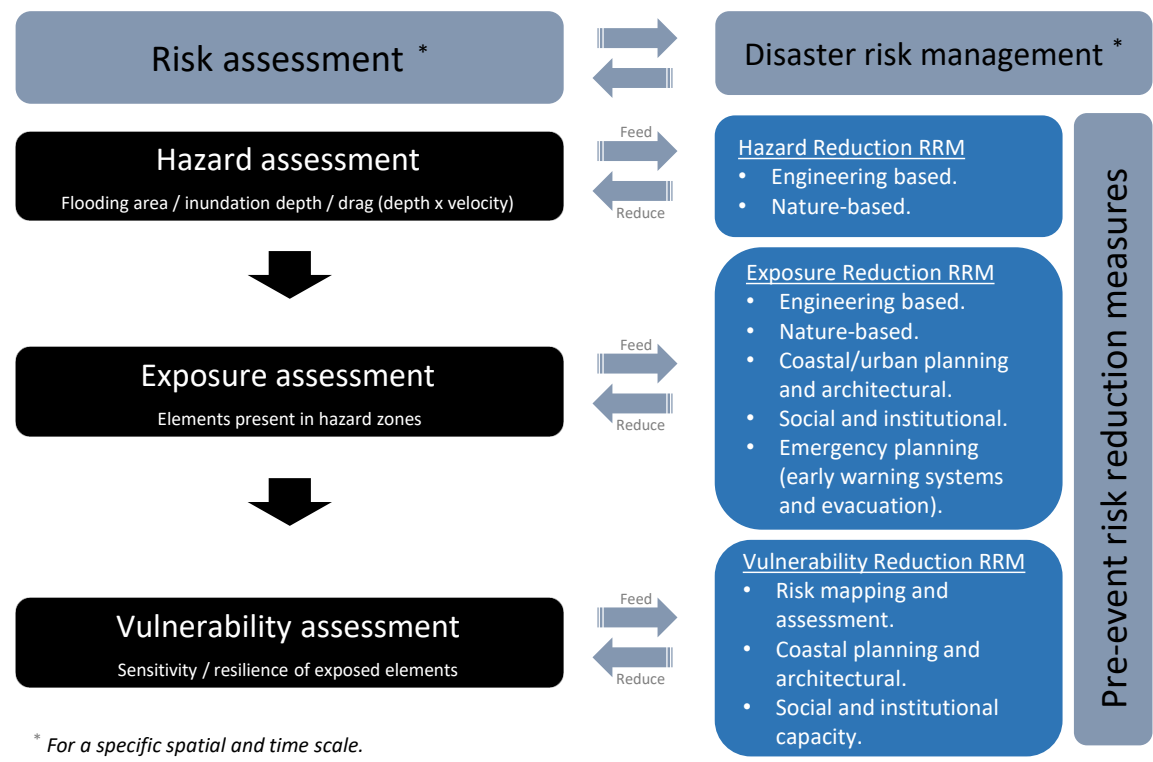

Figure 5. Interactions between the different components of risk assessment and the pre-event approaches of risk reduction measures. 
educational and capacity building measures, and (iii) emergency measures. Risk assessment and planning is the first step of the risk management cycle, providing essential guidance within the decision-making process. The social and institutional measures enhance the knowledge and capacities developed by communities and individuals to effectively anticipate and respond to the impacts of likely, imminent or current hazard events, as stated by UN (2016). The emergency measures ensure public safety by issuing alerts and planning the evacuation of people and certain goods (e.g. vessels) at risk to safe areas or shelters when a tsunami is detected. There are some other preparedness measures, which are oriented to the post-event phase of the disaster management, such as contingency planning, stockpiling of equipment and supplies and arrangement for coordination.

Prevention refers to actions that aim at shielding or protecting from the hazard through activities taken in advance, by reducing the hazard itself, the exposure to that hazard or the vulnerability of the exposed people or goods. These include (i) engineering-based measures, (ii) nature-based measures, and (iii) coastal planning and architectural measures. The engineering-based measures, i.e. controlled disruption of natural processes by using long term man-made structures (hard engineering solution), help to reduce the intensity of the hazard. The nature-based measures, i.e. the use of ecological principles and practices (soft engineering solution), help to reduce the intensity of the hazard and to enhance the safety of coastal areas while boosting ecological wealth, improving aesthetics, and saving money. The coastal planning and architectural measures, i.e. regulations and good practices, reduce exposure and vulnerability that is mainly related to the infrastructure dimension.

Table 2 shows the set of RRM developed (based on UNFCCC, 1999; Nicholls et al., 2007; UNESCO, 2009a; Linham and Nicholls, 2010), organized by strategies, approaches and specific goals.

The catalogue has been developed following these concepts and structure. Each measure is analysed and characterized by means of individual RRM-cards that include the specific objective pursued and description of the measure in several sections: rationale, preliminary requirements, supplementary measures, efficiency, durability and initial cost analysis. Each card includes a list of stakeholders involved in the implementation of the specific RRM in Oman, and the estimation of the current capacity for implementation, based on the information provided by the stakeholder panel of experts. Each card also contains a scheme, several figures and a suitability analysis, which is performed through a SWOT analysis. Finally, it is incorporated a specific bibliographic reference list that permits a deeper study of each measure.

This RRM catalogue is the basis for the next step, the selection and prioritization of the specific set of countermeasures for each area. It is also worth mentioning that a combination of measures from different approaches often offers an effective risk reduction strategy, even enhancing the perfor-

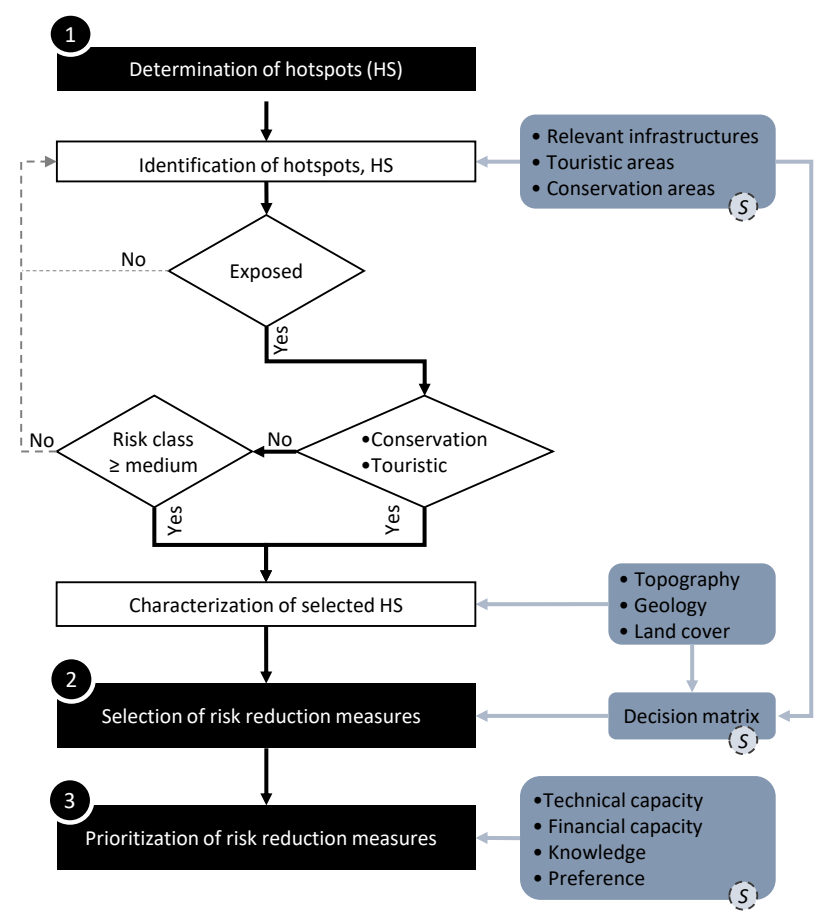

Figure 6. Scheme of the methodology for the prioritization of recommended tsunami risk reduction measures ( $S$ : participation of stakeholder panel of local and international experts on coastal and risk management).

mance of the individual measures when implemented at the same time.

The methodology for the selection and prioritization of the RRM has been designed to ensure its adequacy for sitespecific conditions at local scales among those proposed in the catalogue. It is summarized in three main steps (see Fig. 6): (i) determination of the hotspots, (ii) selection of the recommended RRM through a decision matrix and (iii) the prioritization of RRM.

\subsubsection{Determination of hotspots}

The first step is the determination of hotspots, which are the zones in which RRM will be further proposed. Coastal hotspots (HS) are identified in consensus with the stakeholder panel, including built-up populated areas and the following areas of special interest: (i) relevant infrastructure such as transport and communications infrastructure (airports and sea-ports), supply infrastructure (power and water) and dangerous infrastructure (refineries, dangerous industrial areas and military bases); (ii) touristic regions, where there is significant seasonal variation in the population; and (iii) environmental conservation areas, to consider the fragile and complex systems where the coastal ecosystems converge with the marine dynamics and human activities, which include lagoons, mangroves and turtle nesting areas. 
Table 2. Strategies, approaches, measures and specific goals for risk reduction derived from coastal risk due to tsunami hazard $(H$ : hazard, $E_{\mathrm{p}}$ : permanent exposure, $E_{\mathrm{t}}$ : temporary exposure, $V$ : vulnerability).

\begin{tabular}{|c|c|c|c|c|}
\hline Strategy & Approach & Code & Mitigation measure & Specific goal \\
\hline \multirow[t]{6}{*}{ Preparedness } & Risk mapping and assessment & RA. 1 & Hazard, vulnerability and risk & $V$ \\
\hline & \multirow[t]{3}{*}{ Social and institutional capacity } & PR. 1 & Raising awareness & \multirow[t]{3}{*}{$E_{\mathrm{t}}$ and $V$} \\
\hline & & PR. 2 & Capacity building & \\
\hline & & PR. 3 & Education & \\
\hline & \multirow[t]{2}{*}{ Emergency planning } & EM. 1 & Early warning systems & \multirow[t]{2}{*}{$E_{\mathrm{t}}$} \\
\hline & & EM. 2 & Evacuation planning & \\
\hline \multirow[t]{12}{*}{ Prevention } & \multirow[t]{4}{*}{ Engineering-based } & EN. 1 & Seawalls and sea dykes & \multirow[t]{4}{*}{$H$} \\
\hline & & EN. 2 & Breakwaters & \\
\hline & & EN. 3 & Movable barriers and closure dams & \\
\hline & & EN. 4 & Land claim & \\
\hline & \multirow[t]{5}{*}{ Nature-based } & NA. 1 & Managed realignment & \multirow[t]{5}{*}{$H$} \\
\hline & & NA. 2 & Beach nourishment & \\
\hline & & NA. 3 & Artificial sand dunes and dune restoration & \\
\hline & & NA. 4 & Living shorelines & \\
\hline & & NA. 5 & Wetland restoration & \\
\hline & \multirow[t]{3}{*}{ Coastal planning and architectural } & PL. 1 & Building standards & \multirow[t]{2}{*}{$V$} \\
\hline & & PL. 2 & Flood proofing & \\
\hline & & PL. 3 & Coastal setbacks & $E_{\mathrm{p}}$ \\
\hline
\end{tabular}

After the identification of the HS, it is evaluated whether they are exposed to a tsunami hazard (i.e. located in the flooded area) and if they exceed the risk class threshold as shown in Fig. 6, in order to determine the units that will feed the decision matrix into the second phase. Due to their significance, the scarcity of data when performing the vulnerability assessment and the relevance given by local stakeholders, touristic regions and environmental conservation areas will move to the next step if the HS is exposed, regardless of the risk level. In all other cases, for those HS under very low, low risk or not exposed, no countermeasures will be assigned. The HS characterization is carried out by assigning elevation characteristics (highlighting low-lying areas and wadis), a geological categorization (bare consolidated or non-consolidated substratum) and the land cover (cropland, built-up areas and vegetation-covered areas).

\subsubsection{Selection of risk reduction measures}

The second stage consists of the preliminary assignment of RRM to each HS according to the decision matrix. The matrix, which was validated by the stakeholder panel, is fed by the specific characteristics of each HS and by type of HS, as described previously. Table 3 shows the decision matrix, already sorted by the ratings of the stakeholder panel of experts on coastal risk management in Oman, as explained in Sect. 2.4.3.

The assignment of each recommended measure (highly recommended, recommended or not recommended) is based on the information described in each of the RRM-cards and depends on the characteristics that have determined the type HS. Firstly, the topography of the area, with a focus on the low-lying areas and wadis, where coastal and pluvial flooding occurs on a regular basis, at least annually. Likewise, the geology and land cover is analysed to consider the bedrock and type of land use, that condition the suitability of one or another measure. Finally, as shown in the decision matrix, the type of hotspot also conditions the suitability of the RRM preliminary selection. The sets of RRM obtained according to the decision matrix for each of the determinants are merged, and finally the most restricted recommendation is considered.

\subsubsection{Prioritization of risk reduction measures}

Finally, in the third phase, the prioritization analysis considers the characteristics of each measure, its technical and economic requirements, efficiency and durability, the SWOT 
analysis and the capacity of the country to implement them. In addition to technical criteria, there are subjective aspects, including local knowledge and expertise, which should be taken into account when selecting certain recommended RRM as preferred over others. Results of these preferences, shown in Fig. 7, are also reflected in the sorting of Table 3, based on the last column.

\section{Results}

This section presents two types of results. First, Sect. 3.1 and 3.2 deal with technical results obtained from the application of the methodology to the Sultanate of Oman. Section 3.1 describes the most relevant results of the tsunami risk assessment and Sect. 3.2 describes one example regarding the risk reduction measures selected and prioritized for a specific site. Finally, Sect. 3.3 describes the management tools developed and its usefulness for the tsunami DRR decision-making process.

\subsection{Tsunami risk assessment}

The tsunami hazard analysis indicates that the greater flooded area is located in the northern plain and in one section of the eastern face of the country, as shown in Fig. 8a (the Omani wilayats are sorted from north to south in this and the following graphs). However, the greatest flooded area does not necessarily yield the greatest the impact. In fact, the vulnerability analysis show that the elements at risk are not homogenously distributed along these flooded areas. The greatest values for the exposure are on the northern plain, especially between Shinas and Bawshar wilayats (see Fig. 8b and c). Saham, Suwayq, Al Musanaah, Barka and As Seeb wilayats have the highest percentage of exposed population, all above $10 \%$, the latter two more than $15 \%$, whereas there is almost no exposure in the coastline from Sur to Dalkut wilayats, with most of relative values below $1 \%$. The wilayat of $\mathrm{Al}$ Jazir, despite having a low absolute number of exposed population, represents about $8 \%$ of the total, ranking on the side of the most exposed in relative terms. Regarding the exposure of buildings and infrastructure, the pattern is very similar. The highest rates of exposure take place in the northern area, especially from Sinas to As Seeb wilayat (with exposure values over $40 \%$ ), with the exception of Liwa. In the rest of the country, Jaalan Bani Bu Ali and Al Jazir have the highest values, with $45 \%$ (about 8300 items) and $25 \%$ (about 750 elements), respectively.

The vulnerability assessment reveals the different characteristics of each wilayat in terms of both population and infrastructure, being the highest values correlated to the highest exposure values. In general, the most representative variables of the human vulnerability assessment along the entire coast are the "expatriates" and the "sensitive age groups", both around the $30 \%$ of the total population exposed (Fig. 8b).

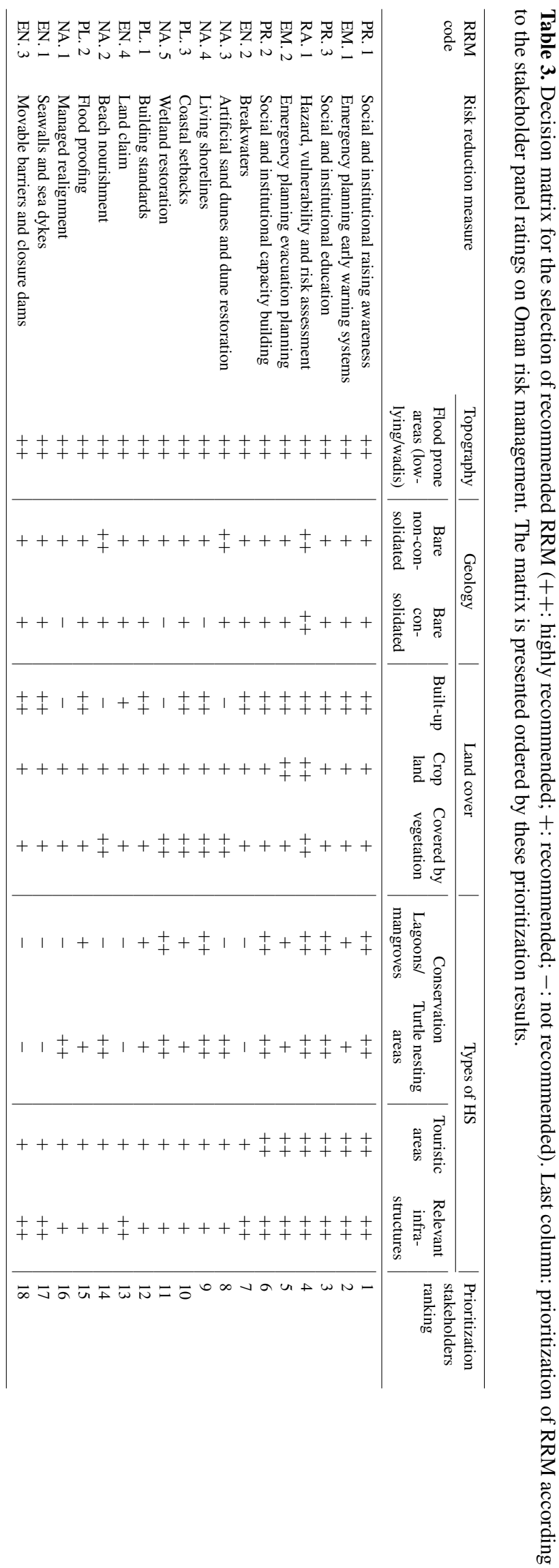

www.nat-hazards-earth-syst-sci.net/18/2241/2018/ 


\section{Tsunami risk reduction measures priority scores}

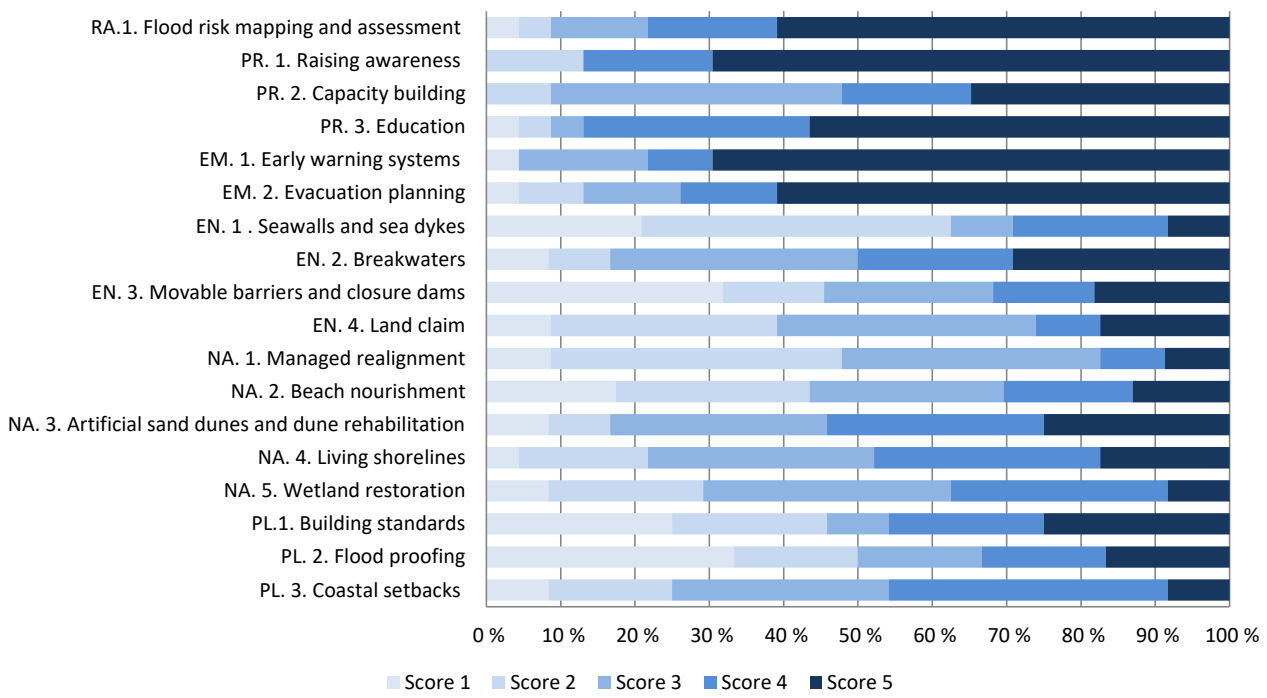

Figure 7. Scoring of the RRM according to the stakeholder panel ratings (1: the least preferred; 5: most preferred).

The variable that contributes less to the human vulnerability is "disabled persons", but even if it is not very representative in relative values (about $2 \%$ of total exposure), it was maintained in the analysis because of its relevance and importance within the risk assessment.

As for the infrastructure dimension (Fig. 8c and d), the vulnerability analysis highlights that the "critical buildings" category is the most affected, being around $96 \%$ of all sensitive and exposed buildings. Around $70 \%$ of the buildings within this class are religious, the wilayats Saham and As Suwayq being the most affected. Despite their lower absolute number, it is necessary to consider the other variables that feed the infrastructure vulnerability analysis due to their significant relevance in case of an emergency (emergency, supply, dangerous and strategic), as described in the risk assessment section. In this sense, Fig. 8d shows their distribution along the coastal wilayats, highlighting Sohar, where 10 petrochemical industries, three container terminals, two bulk liquid terminals, one general cargo terminal and a sugar refinery could be affected. All of these industries are located within the area and surroundings of the Port of Sohar.

Integrated vulnerability results are shown in Fig. 9a for both human and infrastructure dimensions. According to the vulnerability classification, the colour ramp varies from green to red, green being the lowest value of the index and red the highest. Note that, for a better understanding, the representation is at the wilayat level, while the vulnerability analysis is performed exclusively for the potentially inundated area due to the tsunami hazard considered. The highest vulnerability scores mainly corresponds with the wilayats located in the northern plain area. Analysing the differences among them, it may be concluded that the most vulnerable wilayats (sorted from north to south) are Sohar, Saham (highest IVI score), As Suwayq, Barka, As Seeb (highest HVI score) and Bawshar.

Finally, Fig. 9b shows the integrated risk map as a synthesis, indicating the amount of area disaggregated by each risk level and wilayat, which shows the amount of population and infrastructure per level. Therefore, it is shown that the northern area of the country would be the most affected by the tsunami scenario modelled in this work, both because of the greater impact of the hazard and the higher degree of exposure and vulnerability.

Summarizing tsunami risk results, Fig. 10a shows the distribution of the exposed population by risk level and wilayat, the greater consequences being on As Seeb and Barka wilayats. Almost $55 \%$ of the exposed population is located in very high-risk areas and around $25 \%$ in high-risk areas. Regarding the infrastructure dimension, most of the exposed builtup area is located in medium risk zones (about $60 \%$ ), and around a $25 \%$ in high-risk zones. Less than $1 \%$ of the built up areas result in very high infrastructure risk areas. Builtup areas by risk level and wilayat are presented in Fig. 10b, showing that Sohar and As Seeb are the most affected wilayats, both in terms of built-up area exposure and risk level.

\subsection{Tsunami risk reduction in Oman}

The methodology applied for the selection and prioritization of optimal RRM, resulted in the identification of 89 hot spots (HS) along the entire coast of the country, half of them located on the north coast, mainly from Liwa to Sur wilayats. About $25 \%$ of them are concentrated in the southeast area 

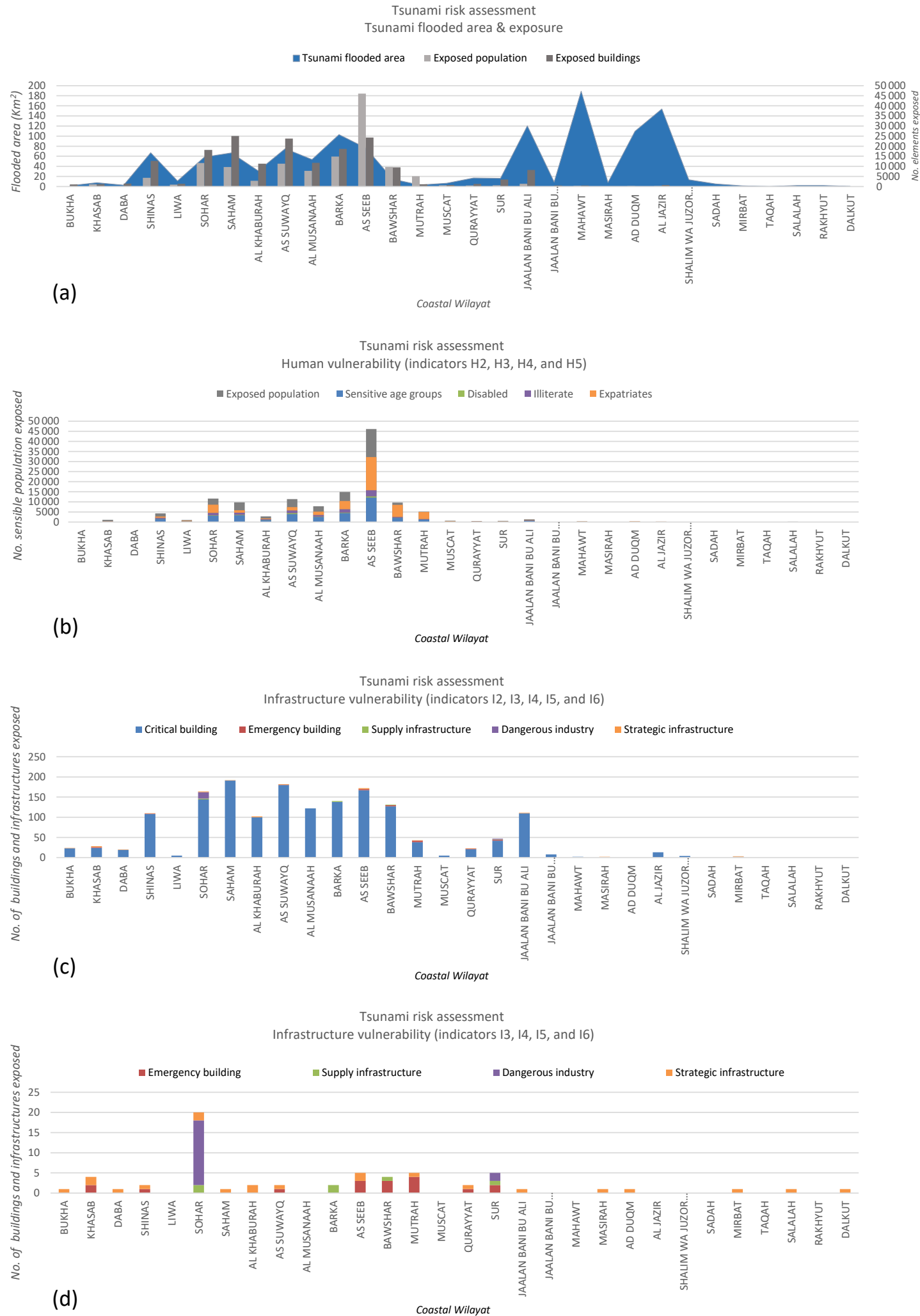

Figure 8. Tsunami risk assessment: (a) tsunami flooded area and exposure, (b) human exposure and vulnerability variables, (c, d) infrastructure exposure and vulnerability variables. 
(a)
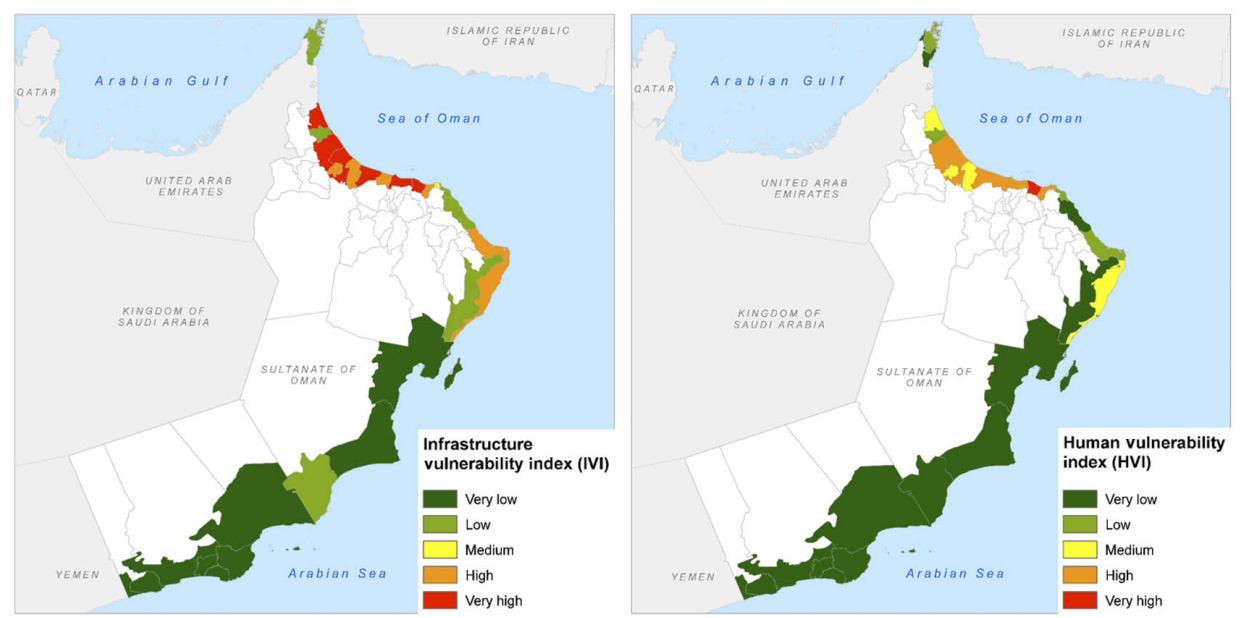

(b)

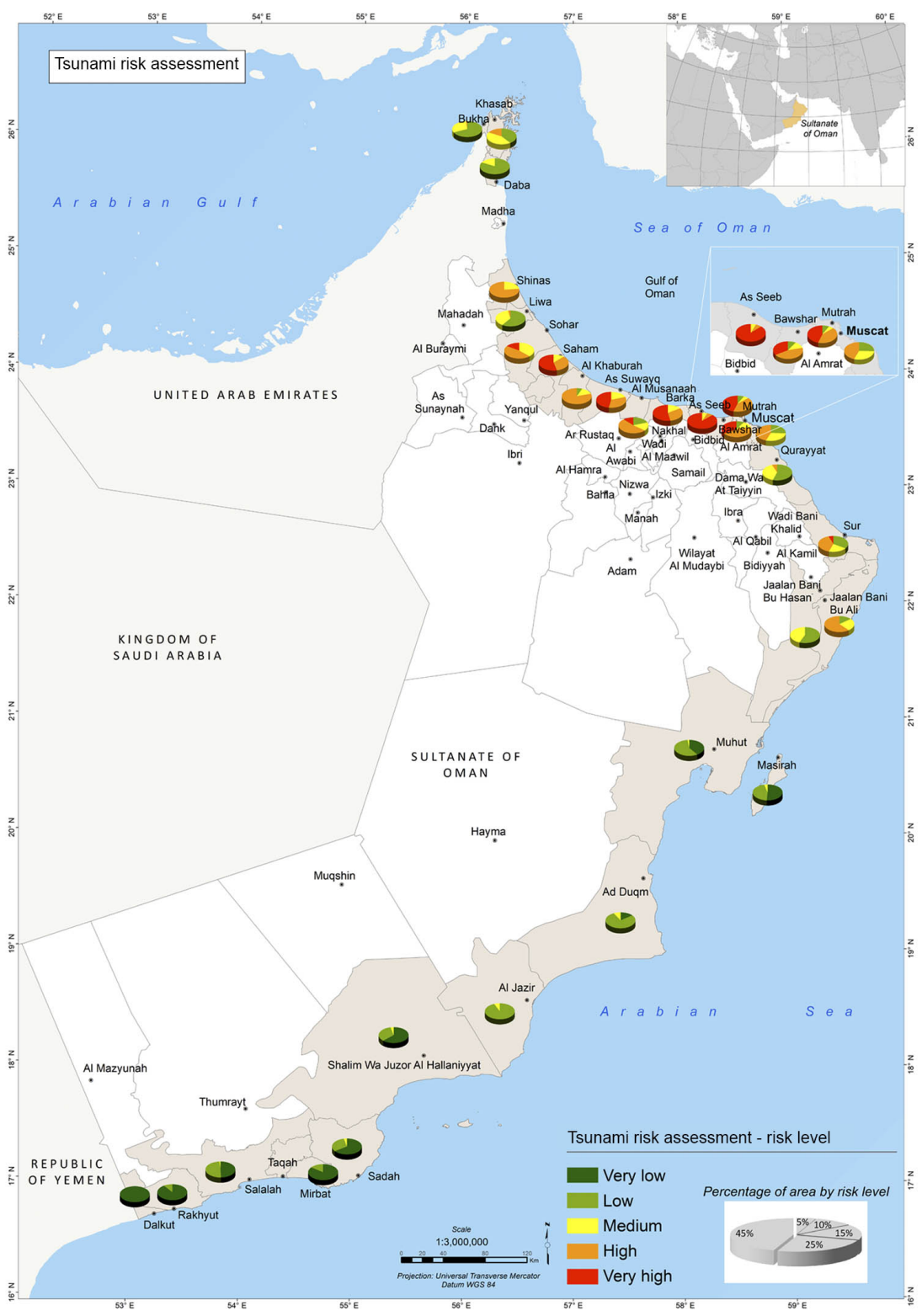

Figure 9. (a) IVI and HVI: infrastructure and human vulnerability indexes; (b) integrated tsunami risk assessment. 


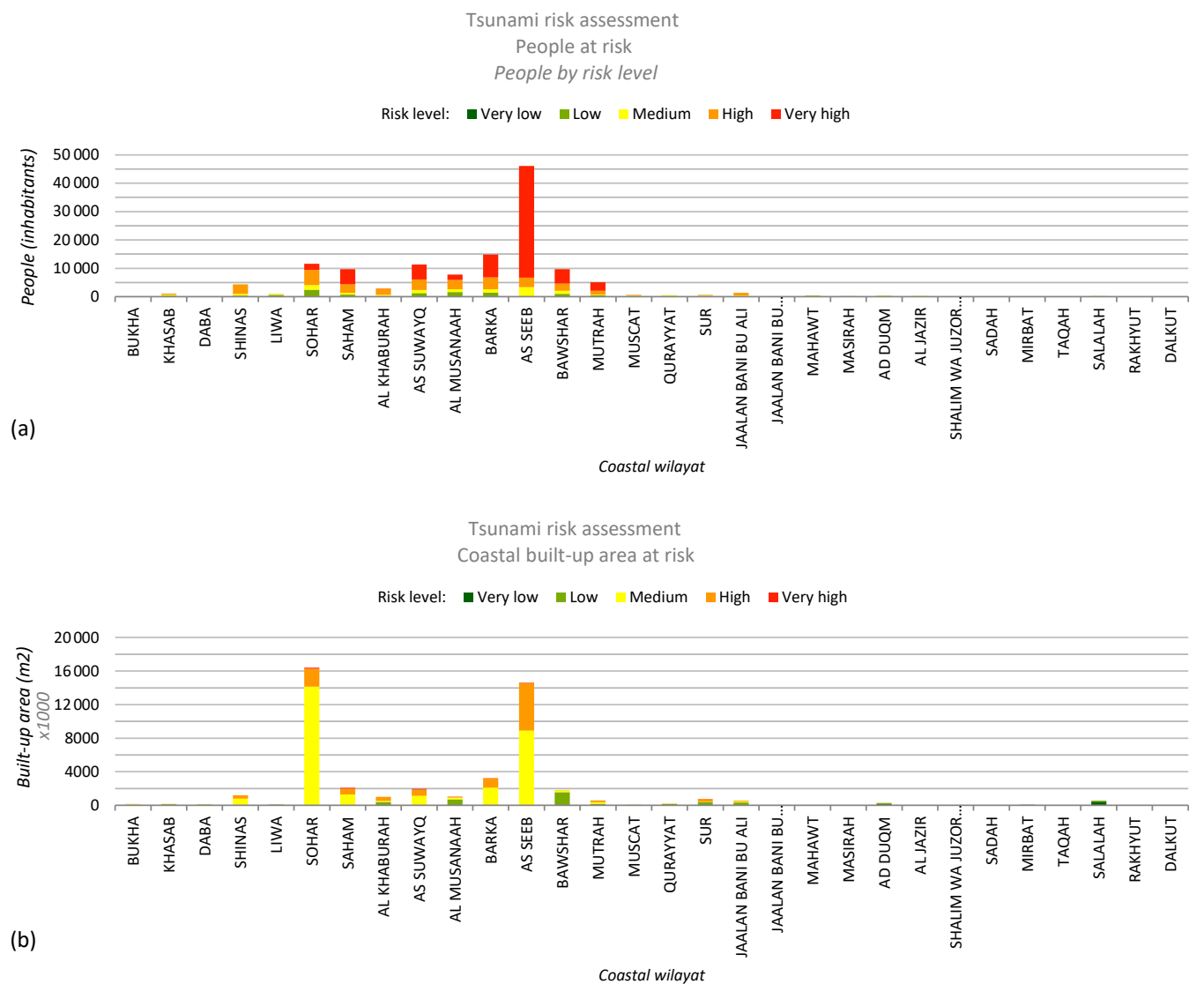

Figure 10. Population and built up areas by risk level.

of the country, especially in wilayats Salalah (12) and Sadah (9). Mashira and Ad Duqm concentrates 10 and 5 HS, respectively. According to the method followed, 79 out of the initial 89 were assigned with a set of RRM.

Next, an example is included to show the whole procedure, focused on the wilayat As Seeb. This wilayat concentrates the largest amount of population exposed to the highest level of risk and is the second wilayat with the greatest infrastructure risk level. The target area (the HS) is the Muscat International Airport and surroundings where, in addition to the airport itself, the building of the Public Authority for Civil Aviation of Oman (PACA) that houses the Multi Hazard Early Warning System and the National Tsunami Warning Centre is located.

Figure 11 shows the selected HS, a simple view of the risk assessment results, a summary of the characterization, and the preliminary set of RRM recommended resulting from the decision matrix. The list is shortened (most preferred on top) according to the prioritization made by the stakeholder panel, based on their knowledge and expertise on the feasibility and the institutional, economic and technological capacity of the country for their implementation.
The first six recommended RRM are related to the preparedness strategy. Based on this result, the implementation of these measures require specific supplementary studies at a greater resolution. These may be high-resolution data collection for the risk analysis (topo-bathymetry, tsunamigenic sources characterization, and vulnerability), in-depth numerical modelling of the flooding physical process, development of a strategy for education of critical groups (most vulnerable members, leaders, institutions, government, educators, etc.), and the cooperation between the government, relief agencies and local communities to enhance the early warning systems and the evacuation planning process.

Regarding the prevention strategy, the first recommended countermeasure is the construction of breakwaters (EN. 2 in Fig. 11). Tsunami breakwaters are usually constructed in the mouth of a bay or estuary, not on open coasts. However, according to the general workflow developed and presented in Fig. 1 (point 6), a detached breakwater has been modelled to understand the efficiency of the measure. The model resulted in a local increase in the elevation of the waves in the study area due to the transformation that the breakwater generates in the tsunami waves. The waves overtop the structure generating an acceleration of the flow that penetrates inland, thus 


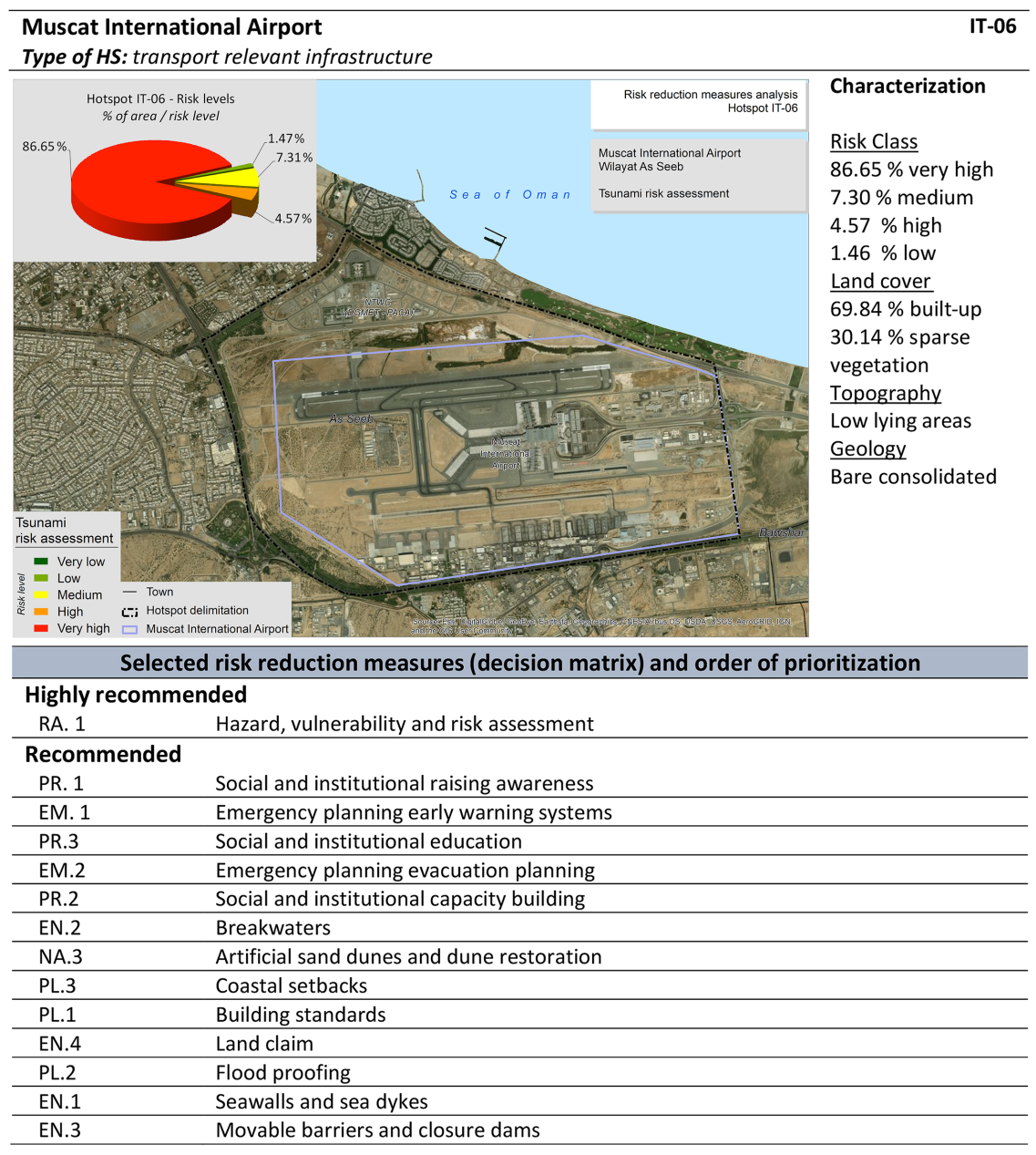

Figure 11. RRM preliminary proposal for the wilayat of As Seeb's relevant infrastructure area. Risk levels correspond to the area of the hotspot at risk, the $79 \%$ of its extent.

increasing the flooded area (see Fig. 12a, b and c). Therefore, although more detailed studies would be necessary, this prevention measure should be discarded at this site. The second recommended prevention measure is the "artificial sand dunes and dune restoration". Accordingly, a more detailed study has been done in a subset of the area by means of modelling an artificial sand dune with a crest height of $3 \mathrm{~m}$, showing an efficient reduction of the flooded area, as shown in Fig. 12d.

Similar procedures for obtaining a preliminary set of RRM have been developed for all the hotspots and for some local areas. In-depth studies should be made to perform a second stage analysis of the recommended countermeasures, considering higher resolution of the hazard analysis and detailed information provided by the vulnerability variables and indicators.

\subsection{Science-based support for the tsunami DRR decision making process}

One of the main objectives of the study is to improve tsunami risk management through the effective use of the results obtained. In this sense, science and technical results are translated into two risk management tools: (i) the Tsunami Hazard, Vulnerability and Risk Atlas, and (ii) the Risk Reduction Measures Handbook. These tools have been implemented and activated by the Directorate General of Meteorology of Oman (DGMET). In addition, a knowledge and technology transfer strategy has been carried out to ensure adequate long-term management.

The Tsunami Hazard, Vulnerability and Risk Atlas, contains a comprehensive description of the methodology applied to assess the risk and all maps from the hazard analysis and vulnerability variables and indices to the final risk results. It is expected to be used as the main source for awareness and education regarding tsunamis and as the basis for 

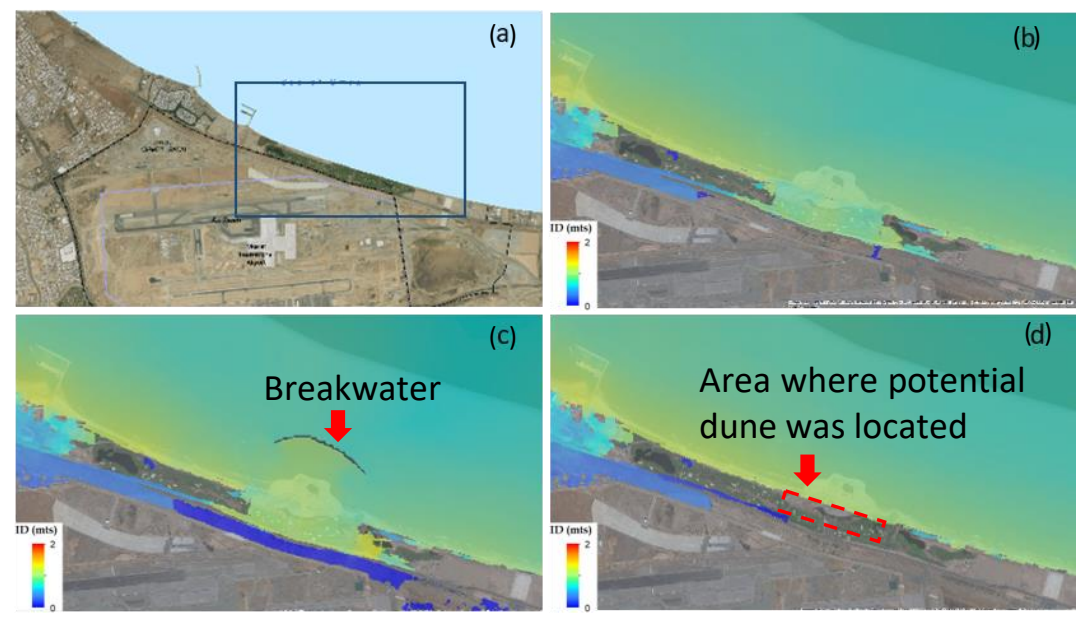

Figure 12. Detailed analysis of preliminary engineering RRM: (a) zoomed sample area, and (b) the modelled flooded area (c) with the breakwater option and (d) with the artificial sand dune option.

further local and detailed studies. In this regard, DGMET efforts are focused in distributing and conducting follow-up meetings to all involved stakeholders, including the Supreme Council for Planning, Ministry of Education, The Public Authority Of Radio And Television, National Committee for Civil Defence (NCCD), Public Authority for Civil Defence and Ambulance and Royal Oman Police-Operation. Follow up meetings are also included in the general strategy to explain the atlas information and discuss the best approaches to utilize such information for the planning and implementation of policies and strategies.

The Tsunami Risk Reduction Measures Handbook is a useful manual to help in the decision-making process related with the tsunami prevention and preparedness. It includes a brief explanation of the methodology developed to select and recommend each set of measures, the catalogue of RRM, containing individual RRM-cards for each countermeasure and the results obtained for each area along the coast of Oman, including the set of recommended RRM for each specific location. Similar to the hazard, vulnerability and risk atlas, DGMET has forwarded the handbook to the government cabinet to distribute among all stakeholders, especially to the Supreme Council for Planning.

Finally, as an additional result of this study, a web based tool to support the tsunami early warning system (called MHRAS) was also developed, implemented and linked to the DGMET Decision Support System.

These tools are the necessary starting point for the development of a strategy for education, raising awareness and capacity building of emergency management authorities and society in general.

\section{Conclusions}

Integrated risk assessments are essential for identifying the most vulnerable communities and worst expected consequences, as well as for designing and planning a roadmap towards risk reduction. For this reason, they should be the basis to link scientific and technical advances with appropriate decision-making and effective risk management.

The methodology presented was developed to build an effective connection between tsunami risk assessment and tsunami risk reduction, with the objective of supporting risk managers by facilitating science-based decision-making in the phases of prevention and preparedness, before an event occurs.

The tsunami hazard modelling, based on potential earthquake sources, permitted to perform an analysis to identify the worst possible scenario, considering the low frequency and high severity nature of the hazard. Thus, it permitted the estimation of the worst negative consequences as the main outcome of the risk assessment. The potentially most affected areas in Oman, in terms of tsunami-prone flooded areas, are the northern plain of the country especially Barka and As Seeb as well as Mahawt and Al Jazir wilayats on the eastern area.

The semi quantitative indicator-based approach for the vulnerability and risk assessment, which integrates risk components (hazard, exposure and vulnerability) and the human and infrastructure dimensions, has been proven useful in discerning the more sensitive areas from a human-centred perspective. The indicators system is helpful for the decisionmaking process in two ways. First, the information at the index and indicator level allows a broad insight of where the exposed elements are and which are more susceptible to suffering the impact of the hazard, i.e. where to focus the efforts towards risk reduction. Second, the approach permits 
tracking back to the variables easily. This information is essential to understand the precise root causes of vulnerability and risk results, to be tackled by adequate and specific DRR measures. In Oman, the most vulnerable areas are located in the northern plain of Oman, highlighting wilayat As Seeb, both in the human and infrastructure dimension and wilayats Saham and Suwayq in the infrastructure dimension. The eastern part, although affected by the inundation, is not so vulnerable. The combination of hazard and vulnerability assessments reveals that the worst expected consequences are for As Seeb and Barka wilayats in terms of human risk and for Sohar and As Seeb in terms of infrastructure risk, according to the tsunami modelled in this work.

As for the connection between risk assessment results and risk management, for each defined tsunami-risk management area, the methodology allows identifying, selecting and prioritizing a preliminary set of suitable and site-specific RRM. This analysis discards non-suitable measures and allows a more in-depth exploration, defining the basis for analysing the feasibility of its implementation, including its technical and economic viability.

The involvement and support of relevant stakeholders in charge of the risk management process is essential for the success and usefulness of the method. Their encouragement has been one of the priorities throughout the application of the method to achieve the main objective of minimizing the consequences that a potential tsunami could trigger in this area.

Through the example shown for the area of Muscat International Airport, the usefulness of the methodology has been illustrated, which can be applied in other parts of the world facing other natural events that may trigger a disaster. Local conditions should be always considered in the definition of the vulnerability indicators, in order to integrate site-specific conditions.

In this sense, with the aim of producing a useful outcome for the risk management, all the results obtained and the detailed description of the method were compiled in two handy management tools. These tools permit the analysis and facilitation of decision-making, to replicate and to update the study by the tsunami disaster managers of Oman, thus contributing to the connection between science-based risk results and disaster risk management.

Data availability. Data are not publicly available.

Competing interests. The authors declare that they have no conflict of interest.

Acknowledgements. The authors thank the Ministry of Transport and Communications of the Government of the Sultanate of Oman (MOTC), the Public Authority for Civil Aviation (PACA) and the
Directorate General of Meteorology (DGMET), for supporting and funding the project "Assessment of Coastal Hazards, Vulnerability and Risk for the Coast of Oman" during the period 2014-2016. We also thank and appreciate the collaboration of the International Oceanographic Commission of the United Nations Educational, Scientific and Cultural Organization personnel (IOC-UNESCO).

Edited by: Ira Didenkulova

Reviewed by: Filippo Zaniboni and one anonymous referee

\section{References}

Abt, S. R., Wittler, R. J., Taylor, A., and Love, D. J.: Human stability in a high flood hazard zone, Water Resour. Bull., 25, 881-890, 1989.

Aguirre-Ayerbe, I.: Propuesta metodológica para la evaluación del riesgo de tsunami en zonas costeras. Aplicación en el litoral de El Salvador, MSc thesis, Earth Science Department, Universidad de Cantabria, Spain, 2011.

Al-Shaqsi, S.: Emergency management in the Arabian Peninsula: A case study from the Sultanate of Oman, in: Comparative Emergency Management: Understanding Disaster Policies, Organizations, and Initiatives from Around the World, edited by: McEntire, D., FEMA, USA, 19 pp., 2012.

Álvarez-Gómez, J. A., Aniel-Quiroga, Í., Gutiérrez-Gutiérrez, O. Q., Larreynaga, J., González, M., Castro, M., Gavidia, F., Aguirre-Ayerbe, I., González-Riancho, P., and Carreño, E.: Tsunami hazard assessment in El Salvador, Central America, from seismic sources through flooding numerical models., Nat. Hazards Earth Syst. Sci., 13, 2927-2939, https://doi.org/10.5194/nhess-13-2927-2013, 2013.

Álvarez-Gómez, J. A., Martínez Parro, L., Aniel-Quiroga, I., González, M., Al-Yahyai, S. Jara,, M. S., Méndez, F., Rueda, A., and Medina, R.: Tsunamigenic seismic sources characterization in the Zagros fold and thrust belt, Implications for tsunami threat in the Persian Gulf, Geophys. Res. Abstr., EGU2014-10951, EGU General Assembly 2014, Vienna, Austria, 2014.

Aniel-Quiroga, Í., Álvarez-Gómez, J. A., González, M., Aguirre Ayerbe, I., Fernández Pérez, F., Jara, M. S., González-Riancho, P., Medina, R., Al-Harthy, S., Al-Yahyai, S., and Al-Hashmi, S.: Tsunami Hazard assessment and Scenarios Database development for the Tsunami Warning System for the coast of Oman, Reducing Tsunami Risk in the Western Indian Ocean conference, Muscat, Oman, 2015.

Beck, M. W. (Ed.): Coasts at Risk: An Assessment of Coastal Risks and the Role of Environmental Solutions. A joint publication of United Nations University - Institute for Environment and $\mathrm{Hu}-$ man Security (UNU-EHS), The Nature Conservancy (TNC) and the Coastal Resources Center (CRC) at the University of Rhode Island Graduate School of Oceanography, 2014.

Berryman, K. (Ed.): Review of tsunami hazard and risk in New Zealand, Geological and Nuclear Sciences (GNS) Client Report 2005/104, p. 149, Institute of Geological \& Nuclear Sciences, New Zealand, 2005.

Birkmann, J., Teichman, K. v., Welle, T., González, M., and Olabarrieta, M.: The unperceived risk to Europe's coasts: tsunamis and the vulnerability of Cadiz, Spain, Nat. Hazards 
Earth Syst. Sci., 10, 2659-2675, https://doi.org/10.5194/nhess10-2659-2010, 2010.

Birkmann, J., Cardona, O. D., Carreño, M. L., Barbat, A. H., Pelling, M., Schneiderbauer, S., Kienberger, S., Keiler, M., Alexander, D., Zeil, P., and Welle, T.: Framing vulnerability, risk and societal responses: the MOVE framework, Nat. Hazards, 67, 193-211, 2013.

Cardona, O. D., Bernal, G. A., Ordaz, M. G., Salgado-Gálvez, M. A., Singh, S. K., Mora, M. G., and Villegas, C. P.: Update on the probabilistic modelling of natural risks at global level: Global Risk Model - Global Earthquake and Tropical Cyclone Hazard Assessment. Disaster Risk Assessment at Country Level for Earthquakes, Tropical Cyclones (Wind and Storm Surge), Floods, Tsunami and Volcanic Eruptions, CIMNE \& INGENIAR Consortium, Background paper for GAR15, Barcelona-Bogotá D.C., Colombia, 2015.

Dall'Osso, F. and Dominey-Howes, D.: A method for assessing the vulnerability of buildings to catastrophic (tsunami) marine flooding, 138 pp., available at: http://www.sydneycoastalcouncils. com.au/Project/Vulnerability_of_Buildings_Tsunami_Flooding (last access: September 2017), 2009.

Dall'Osso, F., Gonella, M., Gabbianelli, G., Withycombe, G., and Dominey-Howes, D.: Assessing the vulnerability of buildings to tsunami in Sydney, Nat. Hazards Earth Syst. Sci., 9, 2015-2026, https://doi.org/10.5194/nhess-9-2015-2009, 2009.

ESPON Monitoring Committee: The Spatial Effects and Management of Natural and Technological Hazards in Europe, European Spatial Observation Network (ESPON 2006) Project 1.3.1., 2006.

Garschagen, M., Hagenlocher, M., Comes, M., Dubbert, M., Sabelfeld, R., Lee, Yew J., Grunewald, L., Lanzendörfer, M., Mucke, P., Neuschäfer, O., Pott, S., Post, J., Schramm, S., Schumann-Bölsche, D., Vandemeulebroecke, B., Welle, T., and Birkmann, J.: World Risk Report 2016, World Risk Report, Bündnis Entwicklung Hilft and UNU-EHS, Bündnis Entwicklung Hilft (Alliance Development Works), Berlin, United Nations University - Institute for Environment and Human Security (UNU-EHS), Bonn, 2016.

González-Riancho, P., Aguirre-Ayerbe, I., García-Aguilar, O., Medina, R., González, M., Aniel-Quiroga, I., Gutiérrez, O. Q., Álvarez-Gómez, J. A., Larreynaga, J., and Gavidia, F.: Integrated tsunami vulnerability and risk assessment: application to the coastal area of El Salvador, Nat. Hazards Earth Syst. Sci., 14, 1223-1244, https://doi.org/10.5194/nhess-14-1223-2014, 2014.

Greiving, S., Fleischhauer, M., and Lückenkötter, J.: A methodology for an integrated risk assessment of spatially relevant hazards, J. Environ. Plann. Man., 49, 1-19, https://doi.org/10.1080/09640560500372800, 2006.

Gutiérrez, O., Aniel-Quiroga, I., and González, M.: Tsunami run up in coastal areas: a methodology to calculate run up in large scale areas, Proc. 34th International Conference on Coastal Engineering, 2014, edited by: Smith, J. M. World Scientific, ASCE, Seoul (Korea), June, 2014.

Harbitz, C. B., Nakamura, Y., Arikawa, T., Baykal, C., Dogan, G. G., Frauenfelder, R., Glimsdal, S., Guler, H. G., Issler, D., Kaiser, G., Kânoğlu, U., Kisacik, D., Kortenhaus, A., Løvholt, F., Maruyama, Y., Sassa, S., Sharghivand, N., Strusinska-Correia, A., Tarakcioglu, G. O., and Yalciner, A. Y.: Risk Assessment and Design of Prevention Structures for Enhanced Tsunami Disaster Resilience (RAPSODI)/EuroJapan Collaboration. Coast. Eng. J., 58, 1640012-1-1640012-37, https://doi.org/10.1142/S057856341640012X, 2016.

Heck, N. H.: List of seismic sea waves, B. Seismol. Soc. Am., 37, 269-286, 1947.

Heidarzadeh, M. and Kijko, A.: A probabilistic tsunami hazard assessment for the Makran subduction zone at the northwestern Indian Ocean, Nat. Hazards, 56, 577-593, 2011.

Heidarzadeh, M. and Satake, K.: New insights into the source of the Makran tsunami of 27 November 1945 from tsunami waveforms and coastal deformation data, Pure Appl. Geophys., 172, 621640, 2014a.

Heidarzadeh, M. and Satake, K.: Possible sources of the tsunami observed in the northwestern Indian Ocean following the 2013 September $24 M_{\mathrm{W}} 7.7$ Pakistan inland earthquake, Geophys. J. Int., 199, 752-766, 2014 b.

Heidarzadeh, M., Pirooz, M. D., Zaker, N. H., Yalciner, A. C., Mokhtari, M., and Esmaeily, A.: Historical tsunami in the Makran Subduction Zone off the southern coasts of Iran and Pakistan and results of numerical modeling, Ocean Eng., 35, 774786, 2008.

Heidarzadeh, M., Pirooz, M. D., and Zaker, N. H.: Modelling the near-field effects of the worst-case tsunami in the Makran subduction zone, Ocean. Eng., 36, 368-376, 2009.

IH Cantabria-MARN (Instituto de Hidráulica Ambiental IH Cantabria, Ministerio de Medio Ambiente y Recursos Naturales de El Salvador MARN): Catálogo de Peligrosidad debida a la inundación por Tsunami en la costa de El Salvador, Spanish Agency for International Development Cooperation (AECID), available at: http://www.ihcantabria.com/es/ proyectos-id/item/839-tsunami-hazard-el-salvador (last access: September 2017), 2010 (in Spanish).

IH Cantabria-MARN (Instituto de Hidráulica Ambiental IH Cantabria, Ministerio de Medio Ambiente y Recursos Naturales de El Salvador MARN): Catálogo de Vulnerabilidad y Riesgo debido a la inundación por Tsunami en la costa de El Salvador, Spanish Agency for International Development Cooperation (AECID), available at: http://www.ihcantabria.com/es/ proyectos-id/item/843-tsunami-vulnerability-risk-el-salvador (last access: September 2017), 2012 (in Spanish).

INFORM: Index for Risk Management. Results 2017. Inter-Agency Standing Committee Reference Group on Risk, Early Warning and Preparedness and European Commission, 2017.

ISO Guide 73:2009: Risk management - Vocabulary, International Electrotechnical Commission/International Organization for Standardization. IEC/ISO, available at: https://www.iso.org/ standard/44651.html (last access: 31 July 2018), 2009.

Jelínek, R., Eckert, S., Zeug, G., and Krausmann, E.: Tsunami Vulnerability and Risk Analysis Applied to the City of Alexandria, Egypt, Tsunami Risk ANd Strategies For the European Region (TRANSFER Project), 2009.

Jelínek, R., Krausmann, E., Gonzalez, M., Álvarez-Gómez, J. L., Birkmann, J., and Welle, T.: Approaches for tsunami risk assessment and application to the city of Cádiz, Spain, Nat. Hazards, 60, 273-293, https://doi.org/10.1007/s11069-011-0009-0, 2012.

Jenks, G. F.: The data model concept in statistical mapping, Int. Yearbook Cartogr., 7, 186-190, 1967.

Jordan, B. R.: Tsunamis of the Arabian Peninsula. A guide of historic events, Science of Tsunami Hazards, 27, 31-46, 2008. 
Jonkman, S. N., Vrijling, J. K., and Vrouwenvelder, A. C. W. M.: Methods for the estimation of loss of life due to floods: a literature review and a proposal for a new method, Nat. Hazards, 46, 353-389, https://doi.org/10.1007/s11069-008-9227-5, 2008.

Jordan, B. R.: Tsunamis of the Arabian Peninsula. A guide of historic events, Science of Tsunami Hazards, 27, 31-46, 2008.

Karvonen, R. A., Hepojoki, H. K., Huhta, H. K., and Louhio, A.: The use of physical models in dam-break analysis. RESCDAM Final Report, Helsinki University of Technology, Helsinki, Finland, 2000.

Koshimura, S., Katada, T., Mofjeld, H. O., and Kawata, Y.: A method for estimating casualties due to the tsunami inundation flow, Nat. Hazards, 39, 265-274, https://doi.org/10.1007/s11069006-0027-5, 2006.

Latcharote, P., Al-Salem, K., Suppasri, A., Pokavanich, T., Toda, S., Jayaramu, Y., Al-Enezi, A., Al-Ragumand, A., and Imamura, F.: Tsunami hazard evaluation for Kuwait and Arabian Gulf due to Makran Subduction Zone and Subaerial landslides, Nat. Hazards, 1-26, https://doi.org/10.1007/s11069-017-3097-7, 2017.

Linham, M. and Nicholls, R. J.: Technologies for Climate Change Adaptation: Coastal erosion and flooding, TNA Guidebook Series, UNEP/GEF, 2010.

Leone, F., Lavigne, F., Paris, R., Denain, J. C., and Vinet, F.: A spatial analysis of the December 26th, 2004 tsunami-induced damages: lessons learned for a better risk assessment integrating buildings vulnerability, Appl. Geogr., 31, 363-375, 2011.

Løvholt, F., Setiadi, N. J., Birkmann, J., Harbitz, C. B., Bach, C., Fernando, N., Kaiser, G., and Nadim, F.: Tsunami risk reduction - are we better prepared today than in 2004?, Int. J. Disast. Risk Re., 10, 127-142, https://doi.org/10.1016/j.ijdrr.2014.07.008, 2014.

Mas, E., Koshimura, S., Suppasri, A., Matsuoka, M., Matsuyama, M., Yoshii, T., Jimenez, C., Yamazaki, F., and Imamura, F.: Developing Tsunami fragility curves using remote sensing and survey data of the 2010 Chilean Tsunami in Dichato, Nat. Hazards Earth Syst. Sci., 12, 2689-2697, https://doi.org/10.5194/nhess12-2689-2012, 2012.

Mokhtari, M.: Tsunami in Makran Region and its effect on the Persian Gulf, in: Tsunami - A Growing Disaster, edited by: Mokharti, M., InTech, 2011.

Nicholls, R. J., Cooper, N., and Townend, I. H.: The management of coastal flooding and erosion, in: Future Flood and Coastal Erosion Risks, edited by: Thorne, C. R., Evans, E. P., and Penning-Rowsell, E. C., Thomas Telford, London, 392-413, https://doi.org/10.1680/ffacer.34495.0023, 2007.

OECD (Organization for Economic Co-operation and Development)/EC-JRC (European Commission Joint Research Centre): Handbook on Constructing Composite Indicators, Methodology and Users Guide, OECD Publications, Paris, 2008.

Okada, Y.: Surface deformation due to shear and tensile faults in a half-space, B. Seismol. Soc. Am., 75, 1135-1154, 1985.

Sato, H., Murakami, H., Kozuki, Y., and Yamamoto, N.: Study on a Simplified Method of Tsunami Risk Assessment, Nat. Hazards, 29, 325-340, https://doi.org/10.1023/A:1024732204299, 2003.

SCHEMA Project: Scenarios for Hazard-induced Emergencies Management, European 6th Framework Programme Project no. 030963, August 2007-October 2010.
Schmidt-Thomé, P. (Ed.): ESPON Project 1.3.1 - Natural and technological hazards and risks affecting the spatial development of European regions, Geological Survey of Finland, 2006.

Shoji, G. and Nakamura, T.: Damage Assessment of Road Bridges Subjected to the 2011 Tohoku Pacific Earthquake Tsunami, J. Disaster Res., 12, 79-89, 2017.

Strunz, G., Post, J., Zosseder, K., Wegscheider, S., Mück, M., Riedlinger, T., Mehl, H., Dech, S., Birkmann, J., Gebert, N., Harjono, H., Anwar, H. Z., Sumaryono, Khomarudin, R. M., and Muhari, A.: Tsunami risk assessment in Indonesia, Nat. Hazards Earth Syst. Sci., 11, 67-82, https://doi.org/10.5194/nhess-11-672011, 2011.

Sugimoto, T., Murakami, H., Kozuki, Y., Nishikawa, K., and Shimada, T.: A Human Damage Prediction Method for Tsunami Disasters Incorporating Evacuation Activities, Nat. Hazards, 29, 587-602, https://doi.org/10.1023/A:1024779724065, 2003.

Suppasri, A., Koshimura, S., and Imamura, F.: Developing tsunami fragility curves based on the satellite remote sensing and the numerical modeling of the 2004 Indian Ocean tsunami in Thailand, Nat. Hazards Earth Syst. Sci., 11, 173-189, https://doi.org/10.5194/nhess-11-173-2011, 2011.

Suppasri, A., Mas, E., Charvet, I., Gunasekera, R., Imai, K., Fukutani, Y., Abe, Y., and Imamura, F.: Building damage characteristics based on surveyed data and fragility curves of the 2011 Great East Japan tsunami, Nat. Hazards, 66, 319-341, 2013.

Suppasri, A., Leelawat, N., Latcharote, P., Roeber, V., Yamashita K., Hayashi, A., Ohira, H., Fukui, K., Hisamatsu, A., Nguyen, D., and Imamura, F.: The 2016 Fukushima earthquake and tsunami: Local tsunami behavior and recommendations for tsunami disaster risk reduction, Int. J. Disast. Risk Re., 21, 323-330, https://doi.org/10.1016/j.ijdrr.2016.12.016, 2017.

Suppasri, A., Fukui, K., Yamashita, K., Leelawat, N., Ohira, H., and Imamura, F.: Developing fragility functions for aquaculture rafts and eelgrass in the case of the 2011 Great East Japan tsunami, Nat. Hazards Earth Syst. Sci., 18, 145-155, https://doi.org/10.5194/nhess-18-145-2018, 2018.

Taubenböck, H., Post, J., Roth, A., Zosseder, K., Strunz, G., and Dech, S.: A conceptual vulnerability and risk framework as outline to identify capabilities of remote sensing, Nat. Hazards Earth Syst. Sci., 8, 409-420, https://doi.org/10.5194/nhess-8409-2008, 2008

Tinti, S., Tonini, R., Bressan, L., Armigliato, A., Gardi, A., Guillande, R., Valencia, N., and Scheer, S.: Handbook of Tsunami Hazard and Damage Scenarios, SCHEMA project (Scenarios for Hazard induced Emergencies Management), European Commission's Joint Research Centre, Institute for the Protection and Security of the Citizen, EU Publications Office, Luxembourg, 2011.

TRANSFER project: Tsunami Risk and Strategies for the European Region, European 6th Framework Programme no. 37058, October 2006-September 2009.

UN (United Nations): Report of the open-ended intergovernmental expert working group on indicators and terminology relating to disaster risk reduction. United Nations General Assembly A/71/644.1 December 2016, New York, USA, 2016.

UNFCCC: Coastal Adaptation Technologies, Bonn, UNFCCC, 1999.

UNESCO (United Nations Educational, Scientific and Cultural Organization): Hazard Awareness and Risk Mitigation in Integrated 
Coastal Management (ICAM), IOC Manual and Guides No. 50, ICAM Dossier No. 5, UNESCO, Paris, 2009a.

UNESCO (United Nations Educational, Scientific and Cultural Organization): Tsunami risk assessment and mitigation for the Indian Ocean, Knowing your tsunami risk - and what to do about it, IOC Manuals and Guides No. 52, UNESCO, Paris, 2009b.

UNISDR (United Nations International Strategy for Disaster Reduction): Living with Risk: a Global Review of Disaster Reduction Initiatives, 2004 version, UN Publications, Geneva, 2004.

UNISDR (United Nations International Strategy for Disaster Reduction): Terminology on Disaster Risk Reduction, UN/ISDR, Geneva, Switzerland, 2009.

UNISDR (United Nations International Strategy for Disaster Reduction): Global Assessment Report on Disaster Risk Redcution, GAR Atlas, available at: https://www.unisdr.org/we/inform/ publications/53086 (last access: 31 July 2018), 2017.

UNISDR/CRED: Tsunami Disaster Risk: Past impacts and projections. United Nations Office for Disaster Risk Reduction (UNISDR), Centre for Research on the Epidemiology of Disasters (CRED), available at: https://www.unisdr.org/we/inform/ publications/50825 (last access: 31 July 2018), 2016.
Valencia, N., Gardi, A., Gauraz, A., Leone, F., and Guillande, R.: New tsunami damage functions developed in the framework of SCHEMA project: application to EuropeanMediterranean coasts, Nat. Hazards Earth Syst. Sci., 11, 28352846, https://doi.org/10.5194/nhess-11-2835-2011, 2011.

Wang, X.: COMCOT User Manual Ver. 1.7, 59 pp., Cornell University, NY, USA, 2009.

Wegscheider, S., Post, J., Zosseder, K., Mück, M., Strunz, G., Riedlinger, T., Muhari, A., and Anwar, H. Z.: Generating tsunami risk knowledge at community level as a base for planning and implementation of risk reduction strategies, Nat. Hazards Earth Syst. Sci., 11, 249-258, https://doi.org/10.5194/nhess-11-2492011, 2011.

Wijetunge, L. J.: A deterministic analysis of tsunami hazard and risk for the southwest coast of Sri Lanka, Cont. Shelf Res., 79, 23-35, 2014.

Xia, J., Falconer, R. A., Wang, Y., and Xiao, X.: New criterion for the stability of a human body in floodwaters, J. Hydraul. Res., 52, 93-104, 2014. 